Review

\title{
Emerging Roles of Lysyl Oxidases in the Cardiovascular System: New Concepts and Therapeutic Challenges
}

\author{
José Martínez-González ${ }^{1,2,3}(\mathbb{D})$, Saray Varona ${ }^{2,3}$, Laia Cañes ${ }^{1,2,3}$, María Galán 2,3,4 (D), \\ Ana M Briones ${ }^{2,5}$, Victoria Cachofeiro ${ }^{2,6}$ and Cristina Rodríguez ${ }^{2,3,4, *(D)}$ \\ 1 Instituto de Investigaciones Biomédicas de Barcelona (IIBB-CSIC), 08036 Barcelona, Spain; \\ jose.martinez@iibb.csic.es (J.M.-G.); lcanes@santpau.cat (L.C.) \\ 2 CIBER de Enfermedades Cardiovasculares, Instituto de Salud Carlos III, 28029 Madrid, Spain; \\ svarona@santpau.cat (S.V.); mgalana@santpau.cat (M.G.); ana.briones@uam.es (A.M.B.); \\ vcara@med.ucm.es (V.C.) \\ 3 Instituto de Investigación Biomédica Sant Pau (IIB-Sant Pau), 08041 Barcelona, Spain \\ 4 Institut de Recerca Hospital de la Santa Creu i Sant Pau-Programa ICCC, 08025 Barcelona, Spain \\ 5 Departmento de Farmacología, Facultad de Medicina, Universidad Autónoma de Madrid, Instituto de \\ Investigación Hospital La Paz, 28029 Madrid, Spain \\ 6 Departamento de Fisiología, Facultad de Medicina, Universidad Complutense de Madrid-Instituto de \\ Investigación Sanitaria Gregorio Marañón (IiSGM), 28040 Madrid, Spain \\ * Correspondence: crodriguezs@santpau.cat
}

Received: 16 September 2019; Accepted: 10 October 2019; Published: 14 October 2019

\begin{abstract}
Lysyl oxidases (LOX and LOX-likes (LOXLs) isoenzymes) belong to a family of copper-dependent enzymes classically involved in the covalent cross-linking of collagen and elastin, a pivotal process that ensures extracellular matrix (ECM) stability and provides the tensile and elastic characteristics of connective tissues. Besides this structural role, in the last years, novel biological properties have been attributed to these enzymes, which can critically influence cardiovascular function. LOX and LOXLs control cell proliferation, migration, adhesion, differentiation, oxidative stress, and transcriptional regulation and, thereby, their dysregulation has been linked to a myriad of cardiovascular pathologies. Lysyl oxidase could modulate virtually all stages of the atherosclerotic process, from endothelial dysfunction and plaque progression to calcification and rupture of advanced and complicated plaques, and contributes to vascular stiffness in hypertension. The alteration of LOX/LOXLs expression underlies the development of other vascular pathologies characterized by a destructive remodeling of the ECM, such as aneurysm and artery dissections, and contributes to the adverse myocardial remodeling and dysfunction in hypertension, myocardial infarction, and obesity. This review examines the most recent advances in the study of LOX and LOXLs biology and their pathophysiological role in cardiovascular diseases with special emphasis on their potential as therapeutic targets.
\end{abstract}

Keywords: lysyl oxidases; cardiovascular diseases; atherosclerosis; aortic aneurysm; vascular calcification; vascular stiffness; myocardial fibrosis

\section{Introduction}

Lysyl oxidase (LOX) is a copper-dependent enzyme which has been classically involved in the oxidative deamination of specific $\varepsilon$-amino groups of lysine and hydroxylysine residues in collagen and elastin, allowing the formation of highly reactive allysine aldehydes and producing hydrogen 
peroxide as by-product $[1,2]$. This reaction initiates the covalent cross-linking of collagen and elastin, which is responsible for the tensile strength and elastic properties of connective tissues.

The LOX family is comprised of five closely related copper-dependent enzymes, LOX, the archetypal member of this family, and four LOX-like isoenzymes (LOXL1, LOXL2, LOXL3, and LOXL4) [3]. These enzymes share a conserved C-terminal region corresponding to the catalytic domain, which consists of the lysine tyrosylquinone (LTQ) cofactor, the copper-binding site, and the cytokine receptor-like domain. The N-terminal regions of these enzymes are structurally unrelated, and their functions are undefined. LOX and LOXL1 contain a basic pro-peptide (PP) region, while LOXL2, LOXL3, and LOXL4 possess four tandem repeats of the scavenger receptor cysteine-rich (SRCR) domains, whose biological function remains unclear (Figure 1). LOX and LOXL1 are synthesized and secreted into the extracellular space as inactive precursors. Then, they are proteolytically processed by bone morphogenetic protein-1 (BMP-1) and other procollagen C-proteinases yielding the catalytically active LOX/LOXL1 forms and their corresponding PPs, in a process in which other extracellular matrix (ECM) components such as fibronectin also participate [4,5] (Figure 2). Whether LOXL2-4 could require a proteolytic processing for their activation is currently unclear.

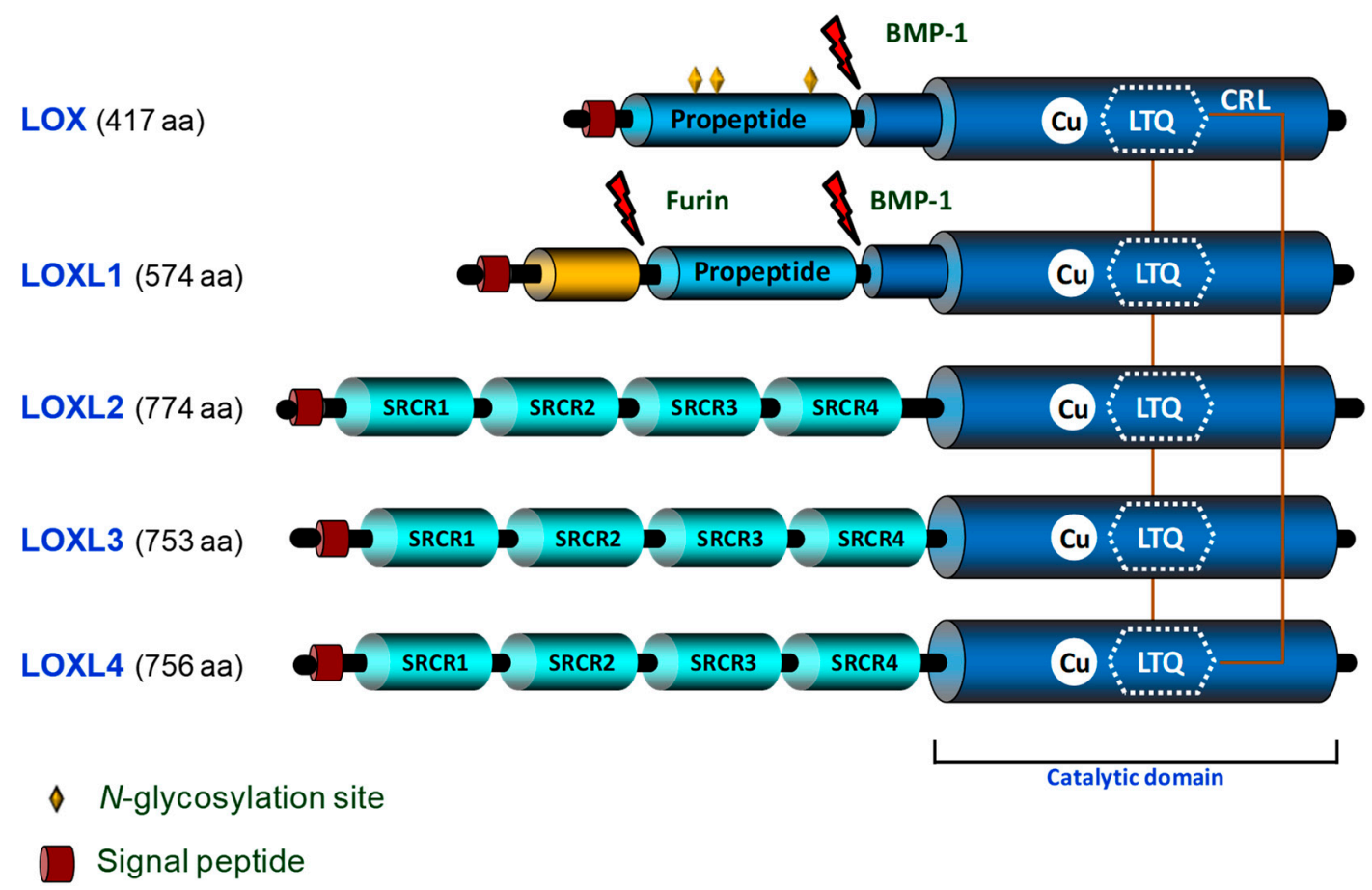

Figure 1. Schematic domain structure and homology of human LOX isoenzymes. The C-terminal regions of LOXs correspond to the highly conserved catalytic domain, which contains the copper binding motif and the lysyl tyrosyl quinone (LTQ) cofactor required for protein conformation and catalytic activity, respectively. Furthermore, the C-terminal domain contains the cytokine receptor-like (CRL) domain. LOX and LOXL1 pro-peptide regions and (Bone morphogenetic protein-1 (BMP-1) cleavage sites, which allow the proteolytic processing of these isoenzymes releasing the active forms, are indicated. The $\mathrm{N}$-glycosylation sites in LOX pro-peptide are marked with diamonds. The four scavenger receptors cysteine rich (SRCR) domains contained by LOXLs isoenzymes in the $N$-terminal region are outlined. 


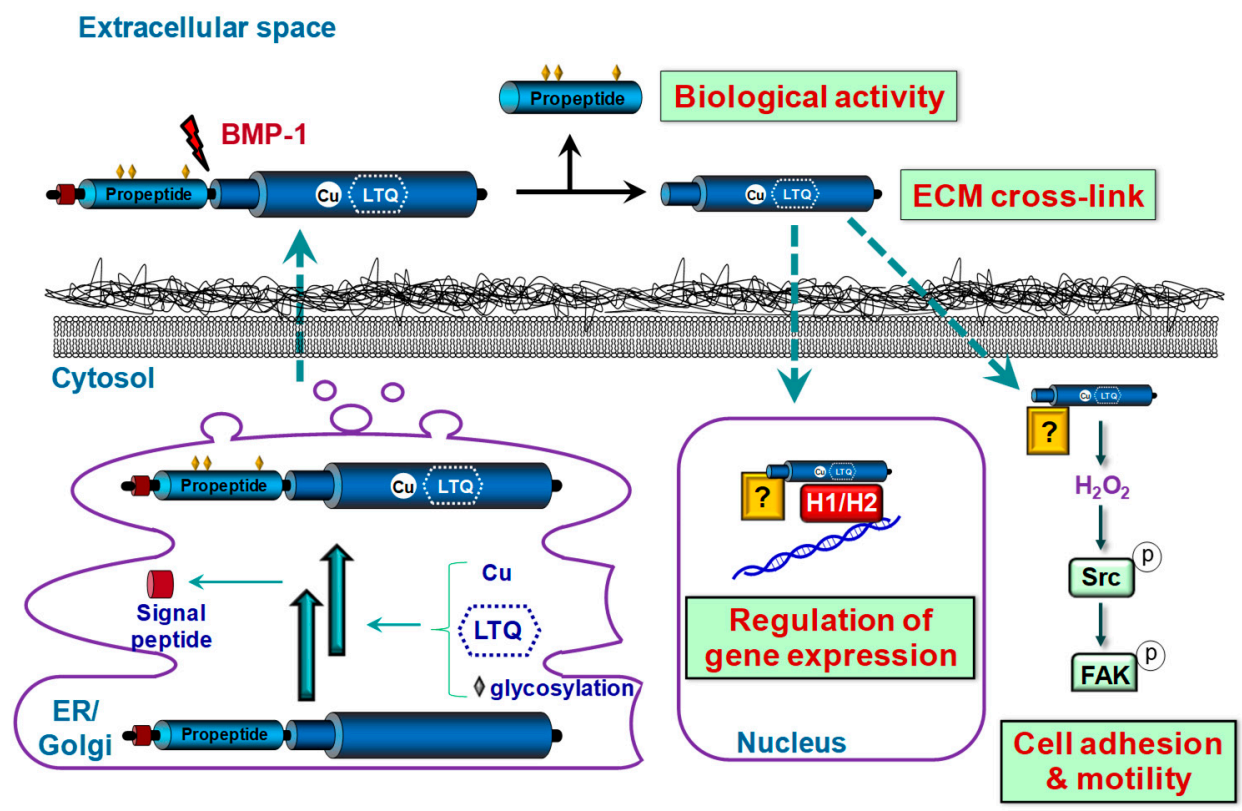

Figure 2. Biological functions and synthesis of LOX. LOX is synthesized as a pre-proenzyme which is post-translationally modified in endoplasmic reticulum (ER) and Golgi. After signal peptide cleavage, copper incorporation, lysyl tyrosyl quinone (LTQ) formation, and glycosylation, the pro-LOX form is released into the extracellular space. Then it is proteolyzed by bone morphogenetic protein (BMP-1) yielding the mature catalytic LOX form, involved in extracellular matrix (ECM) stabilization, and its pro-peptide, which exerts biological functions independently of LOX enzymatic activity. Extracellular LOX could translocate into intracellular compartments by unknown mechanisms. Cytosolic LOX forms participate in the control of cell adhesion and motility in cancer cells, through a mechanism involving the $\mathrm{H}_{2} \mathrm{O}_{2}$-dependent activation of Src-kinase and the subsequent phosphorylation of focal adhesion kinase (FAK). Nuclear LOX regulates gene expression, at least in part, using histones $\mathrm{H}_{1} / \mathrm{H}_{2}$ as substrates.

Beyond ECM maturation, in the last years novel biological functions have been ascribed to LOX and LOXLs (LOX/LOXLs), including the control of epithelial to mesenchymal transition, cell proliferation, migration, adhesion, transformation, and transcriptional regulation. Further, in view of the particular tissue expression patterns of LOX and LOXLs and the phenotypic differences of knockout animal models, it is considered that these isoenzymes would play different physiological roles and that they probably exhibit a dissimilar specificity of substrate. The existence of active intracellular LOX/LOXLs forms, in both the cytoplasm and nucleus, and the biological activity displayed by LOX-PP adds a further degree of complexity and hinders a better knowledge about the role of the LOX family on health and disease [2].

Dysregulation of LOX/LOXLs expression/activity has been linked to several human pathologies including cardiovascular diseases (Figure 3). LOX/LOXLs are expressed in the vascular wall and the heart, and the phenotype of genetically modified animal models for these enzymes support their critical contribution to cardiovascular function and development. LOX knockout mice, which die perinatally, show severe vascular abnormalities, characterized by the presence of aortic aneurysms, aortic tortuosity, extensive fragmentation of elastic fibers, morphological and adhesive alterations of endothelial cells, and discontinuities in the smooth muscle cell layer. LOXL1 deficiency is not lethal, but these animals also evidence vascular defects, although not as severe as those detected in $\mathrm{LOX}^{-/-}$ mice [6]. Moreover, partial perinatal lethality is observed in LOXL2 ${ }^{-/-}$mice associated with heart defects [7]. While no apparent alterations were detected in heart and aorta from LOXL3 knockout mice [8] and $\mathrm{LOXL4}^{-/-}$are not yet available, recent reports suggest their participation in vascular remodeling $[9,10]$. This review summarizes the current knowledge about the contribution of the LOX 
family to cardiovascular diseases, the molecular mechanisms involved in, and discusses their potential interest as pharmacological targets.

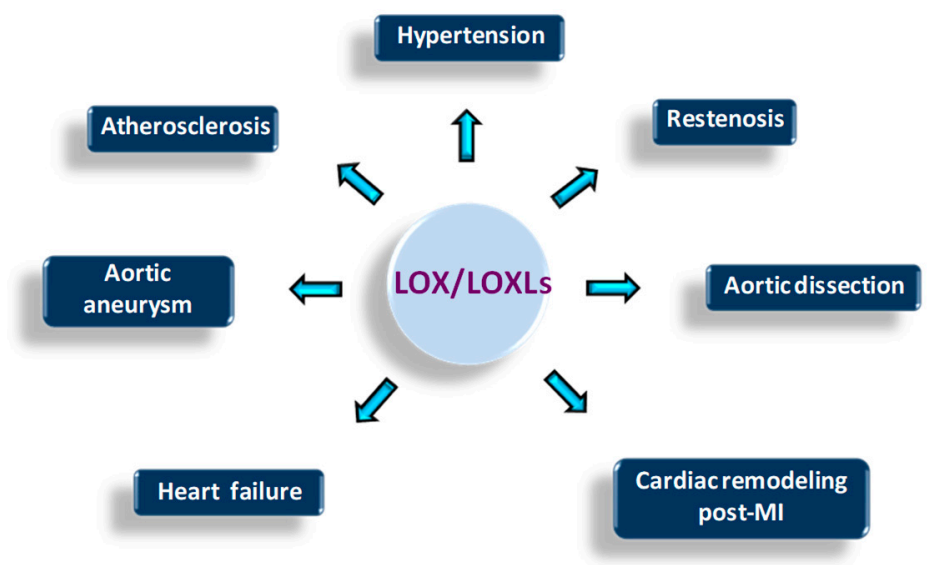

Figure 3. Cardiovascular diseases associated with LOX/LOXLs dysregulation. The disturbance of LOX/LOXLs could underlie the development of several cardiovascular diseases.

\section{Regulation of Vascular Homeostasis by LOX/LOXLs: Pathophysiological Impact}

Different mechanisms link LOX virtually to all stages of the atherosclerotic process, from endothelial dysfunction and plaque progression in the early stages, to calcification and rupture of advanced and complicated plaques (Figure 4). LOX dysregulation seems also to be involved in other vascular pathologies related with atherosclerosis, but mainly characterized by an intense destructuration of ECM such as aneurysms and artery dissections.

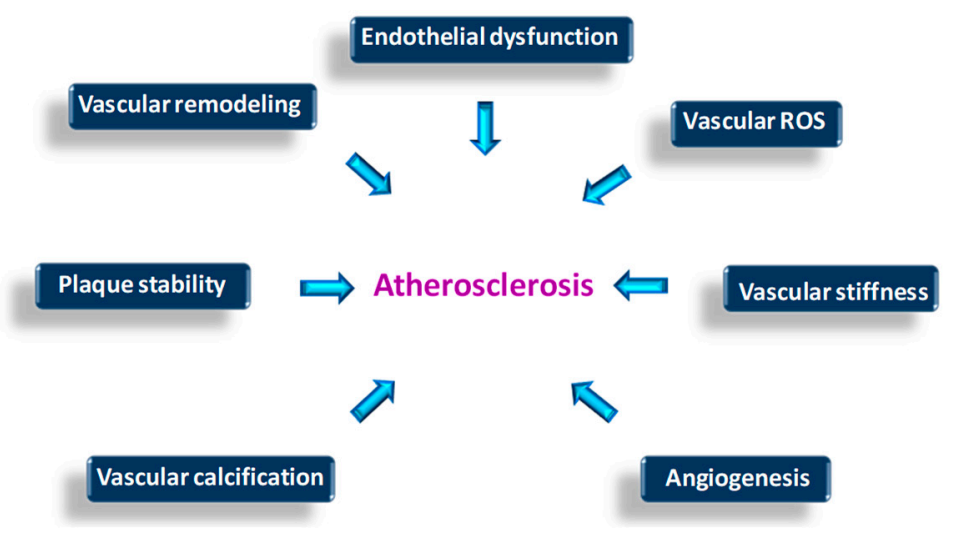

Figure 4. Putative effects of LOX/LOXLs disturbance on the onset and progression of atherosclerosis. The indicated processes could be influenced by LOX/LOXLs dysregulation and affect atherosclerosis progression.

\subsection{Contribution to Arterial Aneurysms and Aortic Dissections}

An aneurysm is a vascular abnormality characterized by the weakness and local dilation of the arterial wall, defined as a 50\% increase in the normal diameter of the vessel. Aortic aneurysms are the most common form of this disease, a severe condition with high morbidity and mortality which can lead to vascular rupture or dissection [11].

The potential involvement of LOX/LOXs in aortic aneurysm was already suggested in the 1990s, when different experimental approaches in animal models supported the importance of LOX in the maintenance of the mechanical stability of the aorta [12-14]. In fact, in rats, the irreversible inhibition of LOX/LOXL activity with $\beta$-aminopropionitrile (BAPN) promoted aortic dilation [12]. Further, the administration of BAPN to angiotensin II (Ang II)-infused ApoE knockout mouse, a classical 
model of aortic abdominal aneurysm (AAA), enhanced AAA incidence [15]. Interestingly, in two other experimental models of AAA in rodents, the elastase- and the $\mathrm{CaCl}_{2}$-induced AAA models, aneurysm development was accompanied by a reduction of LOX expression and activity [13,14]. It should be highlighted that local overexpression of LOX by aortic adenoviral delivery limited the development of established $\mathrm{CaCl}$-induced AAA, at least in part by inhibiting vascular smooth muscle cells (VSMC)-mediated MCP-1 secretion and JNK activity [14,16]. Similarly, in mice, genetic inactivation of LOX, but not that of LOXLs, leads to aortic aneurysms and spontaneous dissections, supporting that the inhibition of this specific isoenzyme could underlie the development of this disease $[17,18]$.

Although experimental data support that LOX inhibition underlies AAA, in humans there is no solid evidence showing a direct causal relationship between LOX/LOXLs and aortic aneurysms, probably because human tissue specimens often come from late stages of aneurysmal disease. Considering that AAA is a focal manifestation of a generalized vascular disturbance [19], LOX has been found upregulated in a recent proteome analysis of internal mammary arteries from patients with AAA [20]. The authors consider the increase in LOX expression a compensatory response triggered by paracrine or endocrine mechanisms to stabilize the aortic wall. Whether LOX activity/expression fails at early stages of human AAA is difficult to assess because of the lack of vascular samples of these stages of the disease.

Regarding thoracic aortic aneuryms (TAA), in 2016 two independent studies simultaneously identified both a loss of function mutation and rare genetic variants in LOX predisposing to TAA [21,22]. Further, LOX protein levels were found downregulated in aortic dissections from ascending aorta compared with healthy specimens [23], in agreement with a previous single case report study [24].

While defective LOX levels have been related to nonsyndromic aneurysms of ascending aorta, enhanced LOX and LOXL1 expression and higher LOX activity have been reported in the aorta from animal models and patients with Marfan syndrome, a systemic connective tissue disorder characterized by severe cardiovascular manifestations, including TAA, acute aortic dissections, and aortic ruptures [25]. The authors argue that the enhanced LOX-dependent collagen deposition and cross-linking in this disease should be regarded as a compensatory response aiming to preserve aortic integrity.

A reduction of vascular LOX expression has also been described in patients with cerebral aneurysm and in experimental models of this disease, an effect associated with the high vascular levels of interleukin-1 $\beta$ and the activation of NFkB signaling characteristics of this disorder [26]. A single nucleotide polymorphism of LOXL2 has been associated with cerebral aneurysms [27], suggesting that the inhibition of LOX/LOXLs could be a key event in the pathophysiology of this disease.

Therefore, aneurysmal diseases are associated with suppression of vascular LOX activity, while experimental interventions or pathophysiological compensatory responses increasing LOX activity seem to preserve artery integrity. Altogether, these data indicate that therapeutic approaches aiming to normalize LOX activity could preserve the mechanical properties of the aortic wall and be a promising strategy to limit the progression of different forms of vascular aneurysms.

\subsection{LOX in Endothelial Dysfunction}

LOX is highly expressed in the endothelium of healthy arteries [28], and multiple evidence associates LOX downregulation with endothelial dysfunction. Indeed, endothelial LOX expression is strongly inhibited by different conditions, which trigger endothelial dysfunction including high levels of low-density lipoproteins (LDL) [29], hyperhomocysteinemia [30], and pro-inflammatory cytokines [31]. LDL increased the exchange of macromolecules across an endothelial monolayer, similarly to the irreversible LOX inhibitor BAPN, suggesting that LOX downregulation by LDL could impair endothelial barrier function [29]. The modulation of LOX by atherogenic concentrations of LDL operates both in vitro and in vivo and has been observed in endothelial cells as well as in VSMC [28,29]. Although the mechanism has not been characterized in detail, it seems to require the internalization of LDL by the LDL receptor (LDLR) and the subsequent lysosome-mediated processing [28]. Hyperhomocystinemia, 
an atherosclerotic risk factor that induces endothelial dysfunction and alters the elastic properties of the vascular wall, also inhibits LOX activity and negatively regulates endothelial LOX expression at the transcriptional level [30]. The detrimental effects of homocysteine on LOX activity have also been observed in small vessels in proliferative diabetic retinopathy [32]. The inhibition of LOX by homocysteine depends on the thiol-group and the generation of reactive oxygen species (ROS) [30]. Although the mechanism has not been further investigated in endothelial cells, in other cell types it involves IL-6, Fli1, and epigenetic CpG methylation [33]. Likewise, pro-inflammatory cytokines impair endothelial function and reduce LOX expression and activity both in vitro and in vivo [31]. TNF $\alpha$ downregulation of LOX mRNA levels and enzymatic activity in endothelial cells depends on TNFR2 and seems to be the consequence of a decrease in LOX transcriptional activity. Interestingly, statins, lipid-lowering drugs widely used in the management of vascular diseases that improve endothelial function, normalize vascular LOX down-regulation induced by TNF $\alpha$ in vitro and by hypercholesterolaemia in vivo [34]. Although inducers of endothelial dysfunction commonly downregulate LOX, in human endothelial cells LOX is upregulated by advanced glycation end products (AGEs) via RAGE/MAPK signaling and NF- $\mathrm{B}$ and AP-1, thereby impairing endothelial homeostasis [35]. Taken together these results indicate that LOX dysregulation underlies endothelial dysfunction elicited by cardiovascular risk factors.

\subsection{LOX in Atherosclerosis Progression and Plaque Instability}

The knowledge on the role of LOX in the onset, progression, and instability of atherosclerotic plaque has been hampered by the lack of studies on this subject in humans, but different approaches in animal models support the contribution of LOX in atherosclerosis.

In an early study conducted by Chvapil et al. [36] in very young chickens (1-2 days old) subjected to a short feeding period with a cholesterol-rich diet, vascular LOX activity was not modified. However, in the porcine model fed a high-fat diet (HFD) we observed that hypercholesterolemia downregulated aortic LOX expression in the earliest stages of the atherosclerotic process (fatty streaks in the aorta after 100 days of diet intervention) [29]. By contrast, in advanced atherosclerosis induced in rabbits fed an atherogenic diet, LOX activity significantly increased, particularly in the aortic arch [37]. In aortic atherosclerosis-prone regions of the ApoE-deficient (ApoE-KO) mice, the expression of LOX as well as several genes encoding for ECM components, such as collagen I and fibronectin, were increased [38]. When these animals were switched to a HFD, despite the extraordinary high plasma cholesterol levels reached, inhibition of LOX by the administration of BAPN reduced atherosclerotic lesion formation $(\approx 50 \%)$. Second harmonic generation 2-photon microscopy revealed reduction in structured collagen in the neointima of lesions from BAPN-treated animals, with no changes in total collagen I [38]. Further, macrophage abundance in lesions was reduced by BAPN, an effect that was related to the low adhesiveness of monocytes/macrophages to the ECM from these animals observed in vitro. Finally, in a recent study, intense LOX immunostaining was located surrounding calcified areas in advanced atherosclerotic lesions from humans [39] (see Section 2.5).

In complicated atherosclerotic plaques, LOX activity could impact on plaque stability. The stability of the atherosclerotic plaque is preserved by the fibrous cap that overlies the lipid core. Acute clinical complications, such as myocardial infarction, are usually caused by a thrombus formed on a vulnerable plaque with a weakened fibrous cap that breaks. Fibrillar collagens synthesized by VSMC are the main components of the fibrous cap, whose biomechanical properties and strength depends on the cross-linking of collagen fibers [40]. In this regard, low LOX activity could lead to defective collagen cross-linking, which would weaken the fibrous cap and favor the presence of soluble forms of collagen highly susceptible to metalloproteinase degradation. In a recent study in atherosclerotic plaques from human carotid endarterectomy specimens, LOX was strongly expressed in areas with ongoing fibrogenesis, in the deeper layers of the fibrous cap and around the necrotic core enriched in CD163 + macrophages (M2 macrophages with profibrotic and anti-inflammatory functions) [41]. In this study, higher levels of LOX were detected in more stable plaques and, interestingly, high levels of LOX 
mRNA in carotid plaques were associated with a lower incidence of myocardial infarction during the follow-up. Mediators of inflammation produced by activated macrophages, $\mathrm{T}$ cells, and other inflammatory cells present in unstable plaques may control LOX expression and hence plaque stability. Interferon $\gamma(\operatorname{IFN} \gamma)$, a cytokine involved in matrix remodeling and induced in ruptured atherosclerotic plaques, reduces collagen I synthesis [42] and downregulates LOX in VSMC by both transcriptional and post-transcriptional mechanisms [43]. Atherosclerotic lesions of mice with increased T-cell activation shows reduced LOX expression and collagen cross-linking, probably due to the inhibition of LOX by cytokines produced by activated T cells [44]. Conversely, in atherosclerosis-prone mice, osteoprotegerin (OPG) promoted VSMC accumulation, LOX upregulation, LOX-dependent collagen fiber maturation, and the formation of stable fibrous caps [45]. Therefore, LOX-dependent collagen cross-linking could play a relevant role in limiting clinical complications by stabilizing atherosclerotic lesions and preventing fibrous cap rupture. It should be taken in mind, however, that the modulation of LOX and LOXLs such as LOXL2 by hypoxia $[10,46]$ and their role in neovascularization, could also indirectly affect plaque stability. Further, recent research has evidenced that mice overexpressing LOX in platelets have more severe thrombosis supporting that LOX enhances platelet activation and thrombosis [47]. Specific studies to better establish the role of LOX/LOXLs in plaque instability are still needed.

\subsection{LOX in VSMC, Vascular Remodeling, and Restenosis}

VSMC plays a key role in vascular remodeling, a process which entails cell migration and proliferation, as well as the production and reorganization of the ECM. LOX has been associated with VSMC migration and proliferation and, as the isoform responsible for the $80 \%$ of the LOX activity in aortic VSMC [48], is essential in ECM maturation.

Different growth factors and cytokines that activate VSMC and ECM synthesis increase LOX expression. Transforming growth factor $\beta$ (TGF $\beta$ ) increases LOX expression and activity in VSMC [49] and concomitantly enhances the synthesis of ECM components. Platelet derived growth factor (PDGF), a key mitogen that promotes VSMC migration and proliferation and neointimal growth, also increases LOX expression [50]. Both PDGF-BB and TGF $\beta$ are involved in the cross-talk between endothelial and VSMC induced by low shear stress leading to LOX upregulation and vascular remodeling [51]. Further, LOX participates in vascular remodeling in HFD-fed rats and mediates the profibrotic effects triggered by leptin-induced TGF $\beta$ in VSMC [52]. On the other hand, LOX binding to this cytokine could suppress TGF $\beta$ signaling [53]. The vascular expression of LOX also seems to be highly dependent on granulocyte macrophage colony-stimulating factor (GM-CSF). GM-CSF increases the expression of both LOX and BMP-1 in VSMC, and GM-CSF-deficient mice exhibit low levels of LOX, BMP-1, and tropoelastin, and impaired cross-linkage of elastic fibers [54].

In the past years, novel findings suggest that LOX/LOXLs functions extend beyond their role in the stabilization of the ECM. Indeed, they markedly influence cell chemotactic responses, proliferation, adhesion and migration [55], all of them cellular processes implicated in vascular remodeling. It has been reported that LOX activity is essential to generate optimal chemotactic sensitivity of VSMC to chemo-attractants by oxidizing specific cell surface proteins, such as PDGF receptor- $\beta$ (PDGFR $\beta$ ) [56,57]. Concerning VSMC proliferation, mitogenic stimulation upregulates LOX in rat adult VSMC [49], and a computational method identified LOX as a VSMC gene responsive to proliferative stimulus [58]. In agreement, the expression of LOX and LOXLs increased in pathologies characterized by intense VSMC migration and proliferation. LOX mRNA and protein expression time-dependently increased after balloon injury of the rat carotid artery, preceding maximal collagen accumulation and neointimal thickening [59]. In rabbits undergoing angioplasty, LOX inhibition reduced restenotic rates and constrictive remodeling [60]. Further, all five LOX/LOLXs are dysregulated in clinical and experimental pulmonary hypertension [10], a pathology characterized by increased muscularization due to VSMC migration and proliferation, and perturbed matrix structures in the vessel wall of small pulmonary arteries. However, other studies concluded that LOX restrains VSMC proliferation. Indeed, an inverse correlation between LOX expression and neonatal VSMC proliferation 
has been reported [50]. LOX-PP also inhibited the proliferation of VSMC in culture, and was detected at high levels in vascular lesions of injured arteries, suggesting that it could be part of a feedback mechanism to limit vascular remodeling [61]. Recently, in a transgenic mouse which overexpresses LOX in VSMC (TgLOX ${ }^{\mathrm{VSMC}}$ ) we have shown that cell proliferation was significantly reduced in TgLOXVSMC VSMC [62]. Transgenic VSMC also exhibited low levels of Myh10 (marker of SMC phenotypic switching), PCNA (marker of cell proliferation), and MCP-1, and a reduced activation of Akt and ERK1/2 in response to mitogenic stimuli (Figure 5A). Accordingly, neointimal thickening induced by carotid artery ligation was attenuated in TgLOX ${ }^{\mathrm{VSMC}}$ mice (Figure $5 \mathrm{C}$ ). In vivo and in vitro studies ruled out any contribution of LOX-PP to the antiproliferative activity of LOX on VSMC and evidenced the participation of extracellular and enzymatically active LOX forms [63].
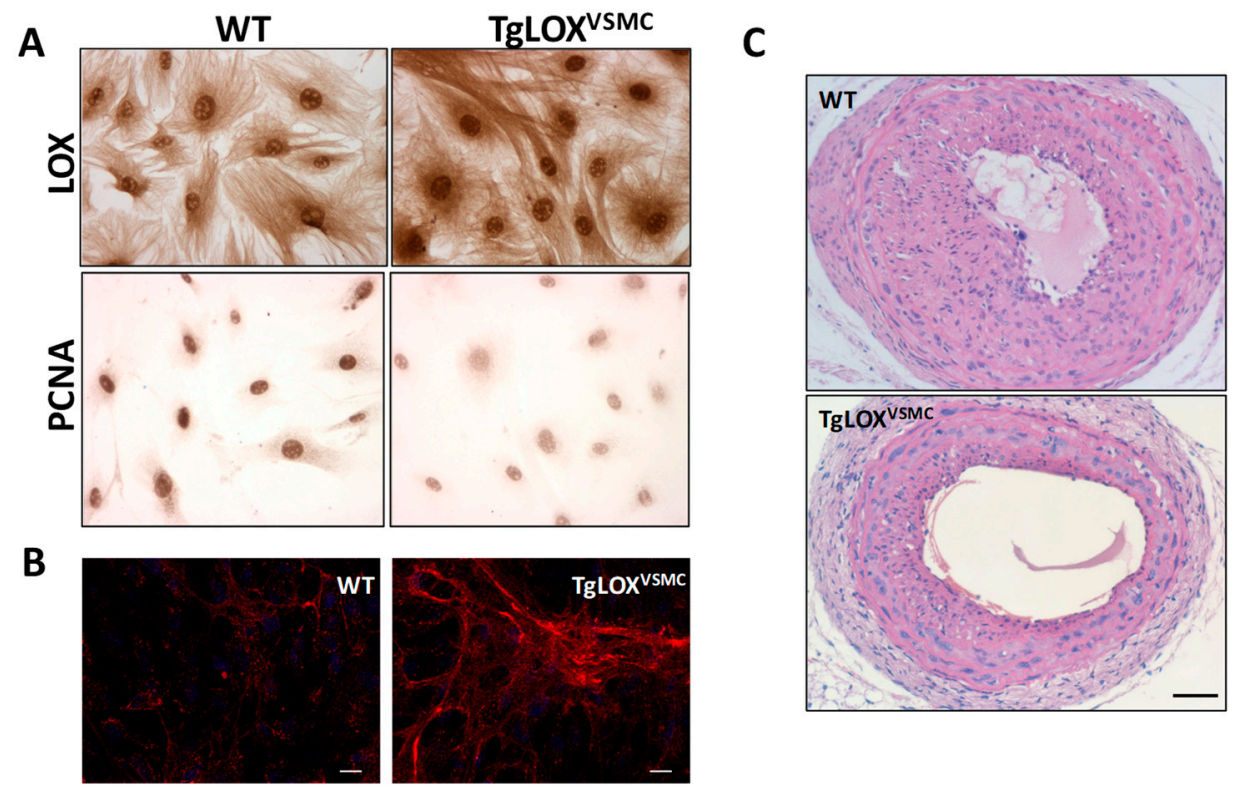

Figure 5. LOX transgenesis limits VSMC proliferation and vascular remodeling. (A) Immunocytochemical analysis of LOX and PCNA, markers of cell proliferation, in aortic VSMC from TgLOXVSMC and WT mice. (B) Collagen type-I deposition (in red) by VSMC from TgLOXVSMC and WT mice visualized by confocal immunofluorescence in nonpermeabilized cells, as described [39]. Cells were incubated with a COL1A1 specific antibody (NB600-408; Novus Biologicals, UK) and nuclei were stained with DAPI. As observed, LOX transgenesis induces the deposition of a thicker and more organized collagen network (Bar: $25 \mu \mathrm{m}$ ). (C) TgLOX ${ }^{\mathrm{VSMC}}$ and WT mice were subjected to left common carotid artery ligation. Injured arteries were harvested 21 days after surgery, fixed in $4 \%$ paraformaldehyde, and embedded in paraffin. Cross-sections at $1.5 \mathrm{~mm}$ from the ligation site were stained with hematoxylin and eosin, as described $[62,63]$. This staining evidenced that LOX overexpression reduces neointimal growth (Bar: $100 \mu \mathrm{m}$ ).

Finally, enzymatically active forms of LOX have been detected in the nucleus of VSMC [64,65]. The biological activity of nuclear LOX remains unraveled, but by affecting chromatin organization they could modulate gene expression, as has been shown for ECM components such as elastin and collagen [66-68], and VSMC proliferation [69].

\subsection{LOX in Vascular Calcification}

In the last decades, several epidemiological studies have demonstrated that vascular calcification is an independent predictor of cardiovascular events and all-cause mortality in the general population [70-72]. Vascular calcification is a complex and tightly organized biological process characterized by the deposition of calcium phosphate, the phenotypic transdifferentiation of vascular cells into osteo/chondroblast-like cells and an active remodeling of the ECM, which seems to play an 
active role in this process. Our recent investigations points towards LOX as a fundamental player in vascular mineralization. Using gain- and loss-of-function approaches we uncovered that LOX contributes to the hyperphosphatemia (HPM)-induced calcification of VSMC and to VSMC-to-osteoblast commitment [39]. In fact, HPM-induced VSMC calcification was accompanied by an up-regulation of LOX expression in both human and murine VSMC. VSMCs isolated from TgLOX ${ }^{\text {VSMC }}$ mice exhibited an exacerbated HPM-induced calcium deposition and a higher increase in the expression of osteogenic factors than wild-type cells. Similarly, in ex vivo studies on aortic rings from these animals exposed to osteogenic media, we evidenced that LOX transgenesis was accompanied by enhanced deposition of calcium. In line with the increased expression of LOX found in human VSMC cultured under osteogenic conditions, we observed that HPM-induced mineralization was associated to a stronger deposition of insoluble collagen [39], highlighting the importance of ECM quality on this process. Moreover, pharmacological inhibition of LOX using BAPN (or LOX knockdown, by RNA interference) limited calcium deposition and the upregulation of osteogenic factors induced by HPM in human VSMC. In contrast with our data, the use of $\beta$-glycerophosphate as an inducer of VSMC calcification in bovine VSMC promotes a downregulation of LOX, discrepancies which are probably due to species-specific responses and disparities in the transduction pathways activated by each procalcifying stimulus [73]. Of note, in human atherosclerotic lesions we found a positive relationship between LOX expression and calcium burden, and similarly enhanced LOX expression and collagen cross-linking have been reported in human calcific aortic valve disease, supporting the pathophysiological relevance of our results $[39,74]$. Considering that vascular calcification is a determinant factor of vascular stiffness, our data evidence the critical involvement of LOX in both processes (see below).

\subsection{LOXs, Vascular Stiffness, and Oxidative Stress: Impact on Hypertension}

Vascular stiffening is a hallmark of vascular aging and pathological processes such as diabetes atherosclerosis and hypertension. It has been established that vascular stiffness, measured as aortic pulse wave velocity (aPWV), is an independent predictive factor of cardiovascular events both in the general population and in subjects with other risk factors [75,76]. Therefore, the control of vascular stiffness could be a promising strategy to ameliorate cardiovascular mortality, especially in hypertension, because arterial stiffening itself has been proposed to be a causal factor in essential hypertension [77].

Vascular stiffness is influenced, among other factors, by the structural elements of the arterial wall, being collagen and elastin particularly determinants. Given the central role of LOX in collagen and elastin cross-linking, we have recently assessed the contribution of LOX to vascular stiffness and hypertension [78]. Mesenteric resistance arteries from TgLOXVSMC were stiffer than those from control animals (Figure 6A). This effect was associated with a decrease in the number and size of fenestrae in the internal elastic lamina (Figure 6B), alterations which have been previously associated to the increased vascular stiffness in animal models of hypertension or during development [79]. The increased vascular stiffness and the disturbance on elastin structure found in TgLOXVSMC mice were ameliorated by BAPN, indicating that these alterations are due to the enhanced vascular LOX activity exhibited by these mice. Additionally, these animals showed an increased production of $\mathrm{H}_{2} \mathrm{O}_{2}$, the by-product of LOX activity, along with a rise in vascular $\mathrm{O}_{2}{ }^{-}$levels, NADPH oxidase activity, NOX-1 expression, and mitochondrial dysfunction [78]. These results evidenced that LOX is a novel source of vascular oxidative stress. It is worth mentioning that the LOX-induced production of ROS is responsible for the enhanced vascular stiffness and the elastic alterations exhibited by LOX transgenic mice, since these disturbances were attenuated by an $\mathrm{H}_{2} \mathrm{O}_{2}$ scavenger and a mitochondria-targeted antioxidant [78]. 
A

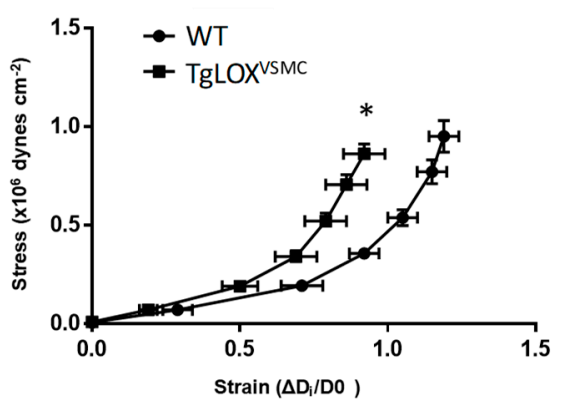

B

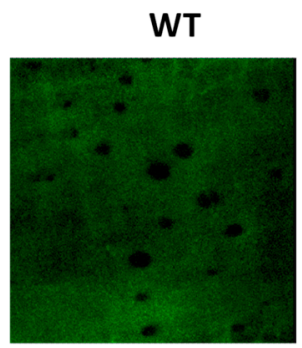

C

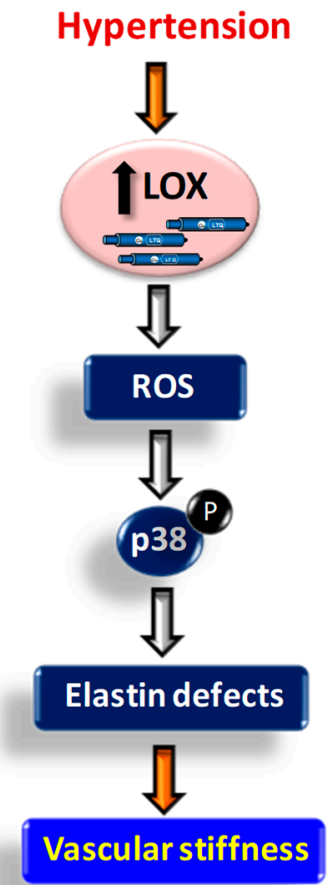

Figure 6. Contribution of LOX to oxidative stress and vascular stiffness in hypertension. (A) The structural and mechanical properties of first-order mesenteric arteries were studied with a pressure myograph (Danish Myo Tech, Aarhus, Denmark) as previously described [78,79]. Stress-strain curves were obtained in arteries from WT and TgLOX ${ }^{\mathrm{VSMC}}$ mice. Vascular stiffness was determined from the stress-strain relationship which is nonlinear; therefore, we obtained the incremental elastic modulus (Einc) by determining the slope of the stress-strain curve of individual animals. Einc values were (mean \pm SEM) WT: $4.11 \pm 0.12(n=6)$; LOX: $5.17 \pm 0.27(n=8) .{ }^{*} p<0.05$ vs. WT by unpaired student t-test. For simplification, statistical analysis is shown in the stress-strain curves. (B) The elastin organization within the internal elastic lamina was studied in segments of mesenteric arteries from TgLOX ${ }^{\mathrm{VSMC}}$ and WT mice using fluorescence confocal microscopy based on the autofluorescent properties of elastin (ex: $488 \mathrm{~nm}$; em: 500-560 nm), as previously described [78,79]. Serial optical sections from the adventitia to the lumen $(z$ step $=0.5 \mu \mathrm{m})$ were captured with a X63 oil objective, by using the $488 \mathrm{~nm}$ line of the confocal microscope. (image size $53 \times 53 \mu \mathrm{m}$ ). (C) Working model showing that LOX induced-oxidative stress alters elastin structure and promotes vascular stiffness in hypertension.

It should be noted that although TgLOXVSMC mice are normotensive, their vascular alterations resemble those from hypertensive models. In fact, our investigations also revealed that LOX is upregulated in the vascular wall of two animal models of hypertension, the spontaneously hypertensive rat (SHR) and Ang II-infused mice, and that the increase in vascular LOX levels results from the hemodynamic effect induced by hypertension. More interestingly, the upregulation of LOX in hypertension is partially responsible for the enhanced vascular stiffness and the higher production of ROS from different sources found in these hypertensive models, as revealed in experiments in which LOX activity was inhibited by BAPN. Likewise, BAPN also abolished the Ang II-induced activation of p38MAPK, responsible for vascular stiffness in hypertension. In accordance, TgLOXVSMC mice exhibit an activation of p38MAPK in the vessel wall, which relies on the higher vascular oxidative stress of these animals, while the inhibition of this kinase limited stiffness and the alterations in elastin structure [78]. Therefore, using complementary gain-of-function and LOX inhibition approaches, we demonstrated that LOX up-regulation is associated with enhanced vascular oxidative stress, which promotes p38MAPK activation, elastin structural alterations, and vascular stiffness in resistance and conductance arteries in hypertension (Figure 6C). 
While our study was focused on elastin, both collagen and elastin cross-linking could contribute to vascular stiffness in hypertension as has been suggested in Ang II-infused animals [80]. In fact, in Ang II-infused mice, BAPN reduced vascular collagen content and cross-linking and vascular stiffness. Then, we cannot discard that the higher vascular stiffness exhibited by TgLOXVSMC mice could be associated with the enhanced deposition of mature collagen that we described in this animal model (Figure 5B) [62]. In any case, our study provides novel information about the key role of LOX in elastin deposition and vascular stiffness.

Although the participation of LOX in vascular stiffness is well demonstrated, its contribution to high blood pressure is still unclear. TgLOX ${ }^{\mathrm{VSMC}}$ mice (at 3 months of age) show normal blood pressure, and although BAPN partially prevented hypertension development in Ang II-infused mice, it was not able to decrease high blood pressure in adult SHR with well-established hypertension [78]. Moreover, newborn $\mathrm{LOX}^{--}$mice show normal blood pressure [81]. It is important to note that arterial stiffening is not the unique determinant of hypertension, but many other mechanisms might operate, and therefore, the contribution of LOX should be specifically addressed. Nevertheless, our results indicate that limiting ECM cross-linkage could ameliorate vessel stiffness and improve the management of patients with cardiovascular disorders.

Regarding other isoenzymes of this family, LOXL2 was identified as a candidate gene in a genome-wide association study for blood pressure and arterial stiffness [82]. Indeed, this enzyme has been recently involved in the regulation of age-associated vascular stiffness, since the increase in PWV induced by aging was ameliorated in LOXL2 ${ }^{+/}$mice [83]. The authors demonstrated that LOXL2 enhances VSMC stiffness and contractility and induces matrix deposition. These results are in agreement with previous reports supporting that the intrinsic stiffening of VSMC also underlies the enhanced aortic stiffness with aging [84]. Whether LOX and other LOXL isoenzymes are involved in the control of intrinsic VSMC stiffening is an issue that deserves further research.

\subsection{LOX and LOXLs in Neovascularization}

Both LOX and LOXL2 have been positively involved in neovascularization, although most of the approaches were focused on tumor angiogenesis. In endothelial cells, the expression of these enzymes is induced by hypoxia, which is a potent angiogenic stimulus [46,85]. In fact, in models of pathological and developmental neovascularization, LOXL2 was detected in angiogenic endothelial cells and tip cells $[85,86]$ and its knockdown in zebrafish embryos significantly suppressed intersegmental vessel circulation. Gain- and loss-of-function studies in HUVEC and microvascular endothelial cells evidenced that LOXL2 contributes to endothelial tube formation through the modulation of endothelial cell migration and proliferation $[85,87]$, and more importantly through collagen IV network assembly, which seems to be critical for capillary formation [85]. It should be noted that in this study on cell migration, tubulogenesis and collagen IV assembly were modestly affected by BAPN, and that a catalytically inactive LOXL2 mutant triggered a similar increase in endothelial cell migration and angiogenic sprouting than wild-type LOXL2. Thus, this suggests that the modulation of these processes by LOXL2 only partially depends on its catalytic activity [85,87]. Indeed, it has been recently suggested that LOXL2 might promote angiogenesis through the regulation of endothelial-to-mesenchymal transition (EndMT) and the activation of PKB/AKT and FAK signaling pathways [87]. However, the contribution of LOXL2 enzymatic activity could not be ruled out because a LOXL2 inhibitory antibody (AB0023) ameliorated basic fibroblast growth factor (bFGF)-induced cell migration and network assembly in HUVEC [88]. The expression of LOXL2 was also specifically induced in tumor endothelial cells which LOXL2 blockade with AB0023 limited tumor vascularization [88,89]. Likewise, small LOXL2 inhibitors decrease tumor angiogenesis and restrict tumor growth [90].

While LOXL2 has been involved in the angiogenic response of both normal and tumoral endothelial cells, evidence regarding the contribution of LOX to neovascularization is weak and the studies were mainly focused on tumor angiogenesis. Tumor-derived LOX drives angiogenesis through PDGFR $\beta$ stimulation and AKT activation leading to an increased production of VEGF [91]. However, it should 
be noted, that this proangiogenic response was exerted by the LOX-induced production of VEGF by tumor cells and that whether this mechanism could operate in vascular endothelial cells in an autocrine manner was not evaluated. A subsequent study evidenced that LOX expression and activity are sharply higher in tumor endothelial cells than in normal cells and that LOX knockdown limits tumor endothelial cell motility and tubulogenesis through the inhibition of FAK signaling [92]. Further, overexpression of both LOX and LOXL2 increased tumor perfused vessel density in different syngeneic models [93]. In contrast, in a mouse model of breast cancer, while the number of tumor-associated endothelial cells was reduced by the LOXL2 targeted antibody AB0023, microvessel density was not significantly modulated by M64, a LOX-specific antibody raised against LOX catalytic domain, supporting a major role of LOXL2 on tumor neovascularization [89].

A recent study reported that LOX-PP inhibits major angiogenic signaling pathways, attenuating HUVEC proliferation, migration and adhesion, and reducing tubulogenesis in the chicken chorioallantoic membrane assay [94]. Although high concentrations of LOX-PP were used in some of these assays, in view of these data, further studies should be necessary to clarify the role of each specific LOX form in physiological and pathological angiogenesis.

In the last years, exosomes raised as key signaling players in the cross-talk between different cell types, as carriers of mRNAs, miRNAs, and proteins. It has been described that LOXL4 could be delivered by hepatocellular carcinoma exosomes and transferred to endothelial cells promoting angiogenesis [95]. Similarly, glioma cell-derived exosomes are internalized by endothelial cells. Exosomes from glioma cells exposed to hypoxia were enriched in LOX and in other relevant proteins in angiogenesis inducing microvascular sprouting. Whether the cargo of LOX in hypoxic exosomes could actively contribute to their pro-angiogenic activity should be, however, clarified [96,97]. Based on these studies and others reporting that LOXL2 levels were increased in endothelial cell-derived exosomes from patients with atherosclerotic cerebrovascular disease, it is tempting to speculate that exosome-derived LOX/LOXLs could have a relevant pathophysiological role in cardiovascular and tumor diseases.

\section{LOX and Heart Disease}

Myocardial interstitial fibrosis is a hallmark of virtually all forms of heart disease, having detrimental consequences on left ventricular (LV) function and actively contributing to the progression of heart failure (HF), a leading cause of death in industrialized countries. Fibrosis, which is a critical determinant of diastolic dysfunction and cardiac stiffness, is characterized by an unbalance between synthesis and degradation of collagen, the major constituent of cardiac ECM. Enhanced cardiac LOX/LOXLs expression/activity has been associated with the adverse myocardial remodeling and dysfunction in animal models of hypertension, cardiac infarct, and obesity [52,98-100]. Interestingly, in the last years different studies in both hypertensive animal models and humans have highlighted the importance of collagen quality beyond collagen amount negatively influencing heart function [99,101-103]. In hypertensive patients with stage C chronic HF, elevated filling pressures are associated with the degree of collagen cross-linking (but not with total collagen) which, in turn, correlates with cardiac LOX expression and more importantly, with an impairment of systolic and diastolic function [102]. In agreement, HF patients with normal ejection fraction showed enhanced myocardial collagen content, but also increased LOX expression and collagen cross-linking, both associated with diastolic dysfunction [103]. The relationship between LOX and diastolic function was also evidenced in a recent study using a new LOX transgenic mouse model. This work shows that myocardial LOX overexpression in mice is associated with an age-dependent disturbance of diastolic function and an accelerated cardiac remodeling [104]. Interestingly, LOX transgenesis also exacerbates Ang II-induced cardiac hypertrophy and systolic dysfunction, enhancing inflammation and ROS production and altering Ang II-dependent signaling. Further, this study uncovers the ability of LOX to promote fibroblast-to-myofibroblast transition, a critical process involved in cardiac fibrosis and remodeling. Similarly, the expression of LOXL2 is increased in patients with ischemic 
or idiopathic dilated cardiomyopathy in which cardiac LOXL2 correlates with collagen cross-linking and with the impairment of diastolic function [105]. Consistent with data described above for LOX, LOXL2 also contributes to cardiac fibroblast reprogramming [105], highlighting the importance of ECM stiffness and composition driving myofibroblast activation [106]. Therefore, these data evidence that the upregulation of LOX/LOXLs in cardiac diseases not only passively contribute to cardiac fibrosis, but actually implies that these enzymes are active players in cardiac dysfunction and disease progression.

Mechanistically, most of the growth factors and cytokines involved in cardiac fibrosis could contribute to the upregulation of LOX and LOXLs in the pathological myocardium. TGF $\beta$, a critical cytokine involved in cardiac fibrosis and remodeling, is an upstream regulator of LOX in cardiac fibroblasts, inducing LOX expression through PI3K/Akt, Smad3, and MAPKs signaling pathways [107]. The enhanced Smad2/3 signaling triggered by TGF $\beta$ also increases c-jun expression which is the ultimate responsible for the TGF $\beta$-mediated activation of LOX transcription [108]. Concomitantly, this response is associated to an enhanced expression of collagens I and III, and BMP-1, resulting in a greater fibrotic response [107]. Similarly, inflammatory factors have been implicated in adverse cardiac remodeling and fibrosis, including TNF $\alpha$ and osteopontin (OPN). Transgenic mice that overexpress TNF- $\alpha$ in the myocardium develop cardiac hypertrophy, fibrosis, dilated diopathy, and premature death [109]. The profibrotic response triggered by TNF $\alpha$ in the myocardium involves the upregulation of LOX due to a TNF $\alpha$-dependent induction of TGF $\beta$ signaling [110]. In turn, OPN, a multifunctional cytokine strongly expressed in the fibrotic myocardium, promotes fibroblast-to-myofibroblast transdifferentiation and upregulates LOX in human fibroblasts. The authors suggest that OPN contributes myocardial stiffness and dysfunction in patients with hypertensive heart disease and HF, at least in part, through the upregulation of LOX and the consequent increase in collagen crosslinking [111]. Likewise, the activation of the TH1 lymphocytic function in mice enhances myocardial LOX expression (LOX and LOXL3) and activity and collagen crosslinking, thereby altering cardiac diastolic function [112]. Although significant efforts have been made to decipher the molecular mechanisms underlying the enhanced ECM crosslinking and LOX/LOXLs expression in the diseased heart, further studies should be addressed to clarify this issue.

Considering the negative impact of an excessive LOX/LOXL-mediated crosslinking of collagen on cardiac function, pharmacological strategies targeting LOX/LOXLs raise as promising therapeutic tools in patients with $\mathrm{HF}$, as discussed below.

\section{LOXs as Pharmacological Targets for Cardiovascular Diseases}

As outlined in this review, the impact of LOX/LOXLs dysregulation on the cardiovascular system and its contribution to different cardiovascular disorders support the interest of these enzymes as novel pharmacological targets for these diseases. The development of LOX/LOXLs-targeted therapeutic tools, however, has been hampered by the unavailability of their crystallographic structure and the fact that both increases and decreases of LOX/LOXLs underlie the development of different cardiovascular diseases that often coexist. Therefore, the therapeutic blockade or, when appropriate, the upregulation of LOX/LOXLs must be thoroughly evaluated to ensure their safety.

The importance of collagen quality in heart performance and the impact of LOX/LOXLs on cardiac fibroblast function highlight the interest of LOX/LOXLs-inhibitory therapies to slow HF progression and limit the detrimental impact of cardiac remodeling in response to myocardial infarction [98,101-103]. Further, an excessive LOXs-dependent cross-linking could interfere with tissue drug distribution, as demonstrated for chemoresistant tumors [93] and, therefore, limiting LOX-induced cardiac stiffness could improve the therapeutic response to established therapies. However, chronic and irreversible LOXs inhibition, such as that achieved by BAPN, might disturb the appropriated ECM scaffold and compromise ventricular integrity. Similarly, although LOX inhibition could decrease vessel stiffness and this might have beneficial effects to protect from cardiovascular events in hypertension, chronic LOX/LOXLs blockade could promote plaque instability, while the risk of vascular aneurysm and 
dissection should not be ignored. It is clear that irreversible inhibitors of LOX/LOXLs, such as BAPN, have enormous limitations as therapeutic tools for chronic use. In fact, it has been reported that chronic administration of BAPN induces neurotoxicity and causes lathyrism, a disorder characterized by connective tissue alterations which notably affects bone mechanical strength and blood vessels [113-116]. To avoid these drawbacks, monoclonal antibodies against LOX and LOXL2 have been developed and proven effective in reducing cardiac fibrosis and dysfunction in experimental models of pressure overload and myocardial infarct $[98,105]$. Simtuzumab, a humanized IgG4 monoclonal antibody against LOXL2, has been tested for its antifibrotic capacity in patients with liver and lung fibrosis and pancreas cancer [117]. However, these clinical trials fail to evidence the efficacy of simtuzumab as an antifibrotic agent despite promising results in preclinical studies in animal models [117]. Whether simtuzumab could provide positive results limiting cardiac fibrosis is currently unknown. Likewise, small molecules that directly inhibit LOXL2 catalytic activity are being developed and tested into healthy volunteer Phase 1 trials [118].

Beyond the development of specific LOX/LOXLs inhibitors, other strategies to reduce LOX activity might involve the use of chelating agents, such as bathocuproine or polyamine chelators, which limit the availability of copper required for the biogenesis of LTQ. Alternatively, BMP-1 inhibition, which would limit the extracellular processing of LOX and LOXL1, could be an additional approach to inhibit LOX.

Another issue to be considered is the potential impact on LOX activity of drugs in use for the management of cardiovascular diseases. Current HF therapies such as torasemide reduced cardiac LOX expression, collagen cross-linking, fibrosis, and LV stiffness in patients with hypertensive HF [119]. Similarly, EXP3179, a metabolite of losartan, reduced cardiac LOX expression and collagen cross-linking in hypertensive rats [120], while, as described above, statins normalize endothelial LOX expression in hyperlipemic animals [34].

\section{Conclusions and Future Challenges}

The experimental findings summarized in this review evidence the key contribution of LOX and LOXLs to multiple aspects of cardiovascular homeostasis, which could be relevant for the development of high-incidence human diseases such as atherosclerosis, HF, arterial aneurysms and aortic dissection. Although significant advancements have been made, overall, the failure of clinical trials in analyzing the antifibrotic properties of simtuzumab indicates the need of a deeper understanding of LOX/LOXLs biology. It is mandatory to identify which are their specific intracellular and extracellular functions and substrates, to develop novel methods allowing to assess the degree of LOX inhibition in the targeted tissues and to identify those patients who will benefit by LOX/LOXLs-targeted therapy. Because regulation of LOX activity could be a double-edged sword, safety concerns should be seriously approached.

Author Contributions: All the authors contribute to the writing and/or revision of the manuscript.

Funding: The authors thank the support provided by the Spanish Ministerio de Ciencia, Innovación y Universidades (MICIU), Instituto de Salud Carlos III (ISCIII) [grants RTI2018-094727-B-100, PI18/0919,] and Agencia de Gestio d'Ajuts Universitaris i de Recerca (AGAUR; program of Support to Research Groups, Ref. 2017-SGR-00333). Our studies were also co-founded by Fondo Europeo de Desarrollo Regional (FEDER), a way to make Europe. L.C. and M.G. were supported by a FI fellowship (AGAUR) and the Miguel de Servet Program (ISCIII; CP15/00126) respectively.

Acknowledgments: We apologize to all colleagues whose important contributions could not be cited due to space limitations.

Conflicts of Interest: The authors declare no conflict of interest. 


\section{References}

1. Rodríguez, C.; Martínez-González, J.; Raposo, B.; Alcudia, J.F.; Guadall, A.; Badimon, L. Regulation of lysyl oxidase in vascular cells: Lysyl oxidase as a new player in cardiovascular diseases. Cardiovasc. Res. 2008, 79, 7-13. [CrossRef] [PubMed]

2. Kagan, H.M.; Li, W. Lysyl oxidase: Properties, specificity, and biological roles inside and outside of the Cell. J. Cell Biochem. 2003, 88, 660-672. [CrossRef] [PubMed]

3. Molnar, J.; Fong, K.S.; He, Q.P.; Hayashi, K.; Kim, Y.; Fong, S.F.; Fogelgren, B.; Szauter, K.M.; Mink, M.; Csiszar, K. Structural and functional diversity of lysyl oxidase and the LOX-like proteins. Biochim. Biophys. Acta 2003, 1647, 220-224. [CrossRef]

4. Rodríguez, C.; Rodríguez-Sinovas, A.; Martínez-González, J. Lysyl oxidase as a potential therapeutic target. Drug News Perspect. 2008, 21, 218-224. [CrossRef] [PubMed]

5. Fogelgren, B.; Polgár, N.; Szauter, K.M.; Ujfaludi, Z.; Laczkó, R.; Fong, K.S.; Csiszar, K. Cellular fibronectin binds to lysyl oxidase with high affinity and is critical for its proteolytic activation. J. Biol. Chem. 2005, 280, 24690-24697. [CrossRef] [PubMed]

6. Liu, X.; Zhao, Y.; Gao, J.; Pawlyk, B.; Starcher, B.; Spencer, J.A.; Yanagisawa, H.; Zuo, J.; Li, T. Elastic fiber homeostasis requires lysyl oxidase-like 1 protein. Nat. Genet. 2004, 36, 178-182. [CrossRef]

7. Martin, A.; Salvador, F.; Moreno-Bueno, G.; Floristán, A.; Ruiz-Herguido, C.; Cuevas, E.P.; Morales, S.; Santos, V.; Csiszar, K.; Dubus, P.; et al. Lysyl oxidase-like 2 represses notch1 expression in the skin to promote squamous cell carcinoma progression. EMBO J. 2015, 34, 1090-1109. [CrossRef]

8. Zhang, J.; Yang, R.; Liu, Z.; Hou, C.; Zong, W.; Zhang, A.; Sun, X.; Gao, J. Loss of lysyl oxidase-like 3 causes cleft palate and spinal deformity in mice. Hum. Mol. Genet. 2015, 24, 6174-6185. [CrossRef]

9. Busnadiego, O.; González-Santamaría, J.; Lagares, D.; Guinea-Viniegra, J.; Pichol-Thievend, C.; Muller, L.; Rodríguez-Pascual, F. LOXL4 is induced by transforming growth factor $\beta 1$ through Smad and JunB/Fra2 and contributes to vascular matrix remodeling. Mol. Cell Biol. 2013, 33, 2388-2401. [CrossRef]

10. Nave, A.H.; Mižíková, I.; Niess, G.; Steenbock, H.; Reichenberger, F.; Talavera, M.L.; Veit, F.; Herold, S.; Mayer, K.; Vadász, I.; et al. Lysyl oxidases play a causal role in vascular remodeling in clinical and experimental pulmonary arterial hypertension. Arterioscler. Thromb. Vasc. Biol. 2014, 34, 1446-1458. [CrossRef]

11. Nordon, I.M.; Hinchliffe, R.J.; Loftus, I.M.; Thompson, M.M. Pathophysiology and epidemiology of abdominal aortic aneurysms. Nat. Rev. Cardiol. 2011, 8, 92-102. [CrossRef] [PubMed]

12. Brüel, A.; Ortoft, G.; Oxlund, H. Inhibition of cross-links in collagen is associated with reduced stiffness of the aorta in young rats. Atherosclerosis 1998, 140, 135-145. [CrossRef]

13. Huffman, M.D.; Curci, J.A.; Moore, G.; Kerns, D.B.; Starcher, B.C.; Thompson, R.W. Functional importance of connective tissue repair during the development of experimental abdominal aortic aneurysms. Surgery 2000, 128, 429-438. [CrossRef] [PubMed]

14. Yoshimura, K.; Aoki, H.; Ikeda, Y.; Fujii, K.; Akiyama, N.; Furutani, A.; Hoshii, Y.; Tanaka, N.; Ricci, R.; Ishihara, T.; et al. Regression of abdominal aortic aneurysm by inhibition of c-Jun N-terminal kinase. Nat. Med. 2005, 11, 1330-1338. [CrossRef] [PubMed]

15. Remus, E.W.; O’Donnell, R.E.; Rafferty, K.; Weiss, D.; Joseph, G.; Csiszar, K.; Fong, S.F.; Taylor, W.R. The role of lysyl oxidase family members in the stabilization of abdominal aortic aneurysms. Am. J. Physiol. Heart Circ. Physiol. 2012, 303, H1067-H1075. [CrossRef] [PubMed]

16. Onoda, M.; Yoshimura, K.; Aoki, H.; Ikeda, Y.; Morikage, N.; Furutani, A.; Matsuzaki, M.; Hamano, K. Lysyl oxidase resolves inflammation by reducing monocyte chemoattractant protein-1 in abdominal aortic aneurysm. Atherosclerosis 2010, 208, 366-369. [CrossRef]

17. Mäki, J.M.; Räsänen, J.; Tikkanen, H.; Sormunen, R.; Mäkikallio, K.; Kivirikko, K.I.; Soininen, R. Inactivation of the lysyl oxidase gene Lox leads to aortic aneurysms, cardiovascular dysfunction, and perinatal death in mice. Circulation 2002, 106, 2503-2509. [CrossRef]

18. Hornstra, I.K.; Birge, S.; Starcher, B.; Bailey, A.J.; Mecham, R.P.; Shapiro, S.D. Lysyl oxidase is required for vascular and diaphragmatic development in mice. J. Biol. Chem. 2003, 278, 14387-14393. [CrossRef]

19. Sonesson, B.; Hansen, F.; Länne, T. Abdominal aortic aneurysm: A general defect in the vasculature with focal manifestations in the abdominal aorta? J. Vasc. Surg. 1997, 26, 247-254. [CrossRef] 
20. Kidholm, C.L.; Beck, H.C.; Madsen, J.B.; Palstrøm, N.B.; Lindholt, J.S.; Rasmussen, L.M. Preliminary analysis of proteome alterations in non-aneurysmal, internal mammary artery tissue from patients with abdominal aortic aneurysms. PLoS ONE 2018, 13, e0192957. [CrossRef]

21. Lee, V.S.; Halabi, C.M.; Hoffman, E.P.; Carmichael, N.; Leshchiner, I.; Lian, C.G.; Bierhals, A.J.; Vuzman, D.; Brigham Genomic Medicine; Mecham, R.P.; et al. Loss of function mutation in LOX causes thoracic aortic aneurysm and dissection in humans. Proc. Natl. Acad. Sci. USA 2016, 113, 8759-8764. [CrossRef] [PubMed]

22. Guo, D.C.; Regalado, E.S.; Gong, L.; Duan, X.; Santos-Cortez, R.L.; Arnaud, P.; Ren, Z.; Cai, B.; Hostetler, E.M.; Moran, R.; et al. LOX mutations predispose to thoracic aortic aneurysms and dissections. Circ. Res. 2016, 118, 928-934. [CrossRef] [PubMed]

23. Yu, Y.; Shi, E.; Gu, T.; Tang, R.; Gao, S.; Wang, Y.; Liu, H. Overexpression of microRNA-30a contributes to the development of aortic dissection by targeting lysyl oxidase. J. Thorac. Cardiovasc. Surg. 2017, 154, 1862-1869. [CrossRef] [PubMed]

24. Sibon, I.; Sommer, P.; Lamaziere, J.M.; Bonnet, J. Lysyl oxidase deficiency: A new cause of human arterial dissection. Heart 2005, 91, e33. [CrossRef] [PubMed]

25. Busnadiego, O.; Gorbenko Del Blanco, D.; González-Santamaría, J.; Habashi, J.P.; Calderon, J.F.; Sandoval, P.; Bedja, D.; Guinea-Viniegra, J.; Lopez-Cabrera, M.; Rosell-Garcia, T.; et al. Elevated expression levels of lysyl oxidases protect against aortic aneurysm progression in Marfan syndrome. J. Mol. Cell Cardiol. 2015, 85, 48-57. [CrossRef]

26. Aoki, T.; Kataoka, H.; Ishibashi, R.; Nozaki, K.; Morishita, R.; Hashimoto, N. Reduced collagen biosynthesis is the hallmark of cerebral aneurysm: Contribution of interleukin-1beta and nuclear factor-kappaB. Arterioscler. Thromb. Vasc. Biol. 2009, 29, 1080-1086. [CrossRef]

27. Akagawa, H.; Narita, A.; Yamada, H.; Tajima, A.; Krischek, B.; Kasuya, H.; Hori, T.; Kubota, M.; Saeki, N.; Hata, A.; et al. Systematic screening of lysyl oxidase-like (LOXL) family genes demonstrates that LOXL2 is a susceptibility gene to intracranial aneurysms. Hum. Genet. 2007, 121, 377-387. [CrossRef]

28. Rodríguez, C.; Raposo, B.; Martínez-González, J.; Alcudia, J.F.; Guadall, A.; Badimon, L. Lysyl oxidase (LOX) expression in the vascular wall: Mechanisms involved in LOX regulation by low density lipoproteins. Clin. Invest. Arterioscler. 2007, 19, 113-121.

29. Rodriguez, C.; Raposo, B.; Martinez-Gonzalez, J.; Casani, L.; Badimon, L. Low density lipoproteins down-regulates lysyl oxidase in vascular endothelial cells and the arterial wall. Arterioscler. Thromb. Vasc. Biol. 2002, 22, 1409-1414. [CrossRef]

30. Raposo, B.; Rodriguez, C.; Martinez-Gonzalez, J.; Badimon, L. High levels of homocysteine inhibit lysyl oxidase (LOX) and down-regulates LOX expression in vascular endothelial cells. Atherosclerosis 2004, 177, 1-8. [CrossRef]

31. Rodríguez, C.; Alcudia, J.F.; Martínez-González, J.; Raposo, B.; Navarro, M.A.; Badimon, L. Lysyl oxidase (LOX) down-regulation by TNFalpha: A new mechanism underlying TNFalpha-induced endothelial dysfunction. Atherosclerosis 2008, 196, 558-564. [CrossRef] [PubMed]

32. Coral, K.; Angayarkanni, N.; Gomathy, N.; Bharathselvi, M.; Pukhraj, R.; Rupak, R. Homocysteine levels in the vitreous of proliferative diabetic retinopathy and rhegmatogenous retinal detachment: Its modulating role on lysyl oxidase. Invest. Ophthalmol. Vis. Sci. 2009, 50, 3607-3612. [CrossRef] [PubMed]

33. Thaler, R.; Agsten, M.; Spitzer, S.; Paschalis, E.P.; Karlic, H.; Klaushofer, K.; Varga, F. Homocysteine suppresses the expression of the collagen cross-linker lysyl oxidase involving IL-6, Fli1, and epigenetic DNA methylation. J. Biol. Chem. 2011, 286, 5578-5588. [CrossRef] [PubMed]

34. Rodríguez, C.; Alcudia, J.F.; Martínez-González, J.; Guadall, A.; Raposo, B.; Sánchez-Gómez, S.; Badimon, L. Statins normalize vascular lysyl oxidase down-regulation induced by proatherogenic risk factors. Cardiovasc. Res. 2009, 83, 595-603. [CrossRef]

35. Adamopoulos, C.; Piperi, C.; Gargalionis, A.N.; Dalagiorgou, G.; Spilioti, E.; Korkolopoulou, P.; Diamanti-Kandarakis, E.; Papavassiliou, A.G. Advanced glycation end products upregulate lysyl oxidase and endothelin-1 in human aortic endothelial cells via parallel activation of ERK1/2-NF-KB and JNK-AP-1 signaling pathways. Cell Mol. Life. Sci. 2016, 73, 1685-1698. [CrossRef]

36. Chvapil, M.; Stith, P.L.; Tillema, L.M.; Carlson, E.C.; Campbell, J.B.; Eskelson, C.D. Early changes in the arterial wall of chickens fed a cholesterol diet. Atherosclerosis 1976, 24, 393-405. [CrossRef]

37. Kagan, H.M.; Raghavan, J.; Hollander, W. Changes in aortic lysyl oxidase activity in diet-induced atherosclerosis in the rabbit. Arteriosclerosis 1981, 1, 287-291. [CrossRef] 
38. Kothapalli, D.; Liu, S.L.; Bae, Y.H.; Monslow, J.; Xu, T.; Hawthorne, E.A.; Byfield, F.J.; Castagnino, P.; Rao, S.; Rader, D.J.; et al. Cardiovascular protection by ApoE and ApoE-HDL linked to suppression of ECM gene expression and arterial stiffening. Cell Rep. 2012, 2, 1259-1271. [CrossRef]

39. Jover, E.; Silvente, A.; Marín, F.; Martínez-González, J.; Orriols, M.; Martinez, C.M.; Puche, C.M.; Valdés, M.; Rodriguez, C.; Hernández-Romero, D. Inhibition of enzymes involved in collagen cross-linking reduces vascular smooth muscle cell calcification. FASEB J. 2018, 32, 4459-4469. [CrossRef]

40. Yamauchi, M.; Sricholpech, M. Lysine post-translational modifications of collagen. Essays Biochem. 2012, 52, 113-133. [CrossRef]

41. Ovchinnikova, O.A.; Folkersen, L.; Persson, J.; Lindeman, J.H.; Ueland, T.; Aukrust, P.; Gavrisheva, N.; Shlyakhto, E.; Paulsson-Berne, G.; Hedin, U.; et al. The collagen cross-linking enzyme lysyl oxidase is associated with the healing of human atherosclerotic lesions. J. Intern. Med. 2014, 276, 525-536. [CrossRef] [PubMed]

42. Butticè, G.; Miller, J.; Wang, L.; Smith, B.D. Interferon-gamma induces major histocompatibility class II transactivator (CIITA), which mediates collagen repression and major histocompatibility class II activation by human aortic smooth muscle cells. Circ. Res. 2006, 98, 472-479. [CrossRef] [PubMed]

43. Song, Y.L.; Ford, J.W.; Gordon, D.; Shanley, C.J. Regulation of lysyl oxidase by interferon-gamma in rat aortic smooth muscle cells. Arterioscler. Thromb. Vasc. Biol. 2000, 20, 982-988. [CrossRef] [PubMed]

44. Ovchinnikova, O.; Robertson, A.K.; Wågsäter, D.; Folco, E.J.; Hyry, M.; Myllyharju, J.; Eriksson, P.; Libby, P.; Hansson, G.K. T-cell activation leads to reduced collagen maturation in atherosclerotic plaques of Apoe(-/-) mice. Am. J. Pathol. 2009, 174, 693-700. [CrossRef]

45. Ovchinnikova, O.; Gylfe, A.; Bailey, L.; Nordström, A.; Rudling, M.; Jung, C.; Bergström, S.; Waldenström, A.; Hansson, G.K.; Nordström, P. Osteoprotegerin promotes fibrous cap formation in atherosclerotic lesions of ApoE-deficient mice-Brief report. Arterioscler. Thromb. Vasc. Biol. 2009, 29, 1478-1480. [CrossRef]

46. Guadall, A.; Orriols, M.; Alcudia, J.F.; Cachofeiro, V.; Martinez-Gonzalez, J.; Rodriguez, C. Hypoxia-induced ROS signaling is required for LOX up-regulation in endothelial cells. Front. Biosci. 2011, 3, 955-967. [CrossRef]

47. Matsuura, S.; Mi, R.; Koupenova, M.; Eliades, A.; Patterson, S.; Toselli, P.; Thon, J.; Italiano, J.E., Jr.; Trackman, P.C.; Papadantonakis, N.; et al. Lysyl oxidase is associated with increased thrombosis and platelet reactivity. Blood 2016, 127, 1493-1501. [CrossRef]

48. Mäki, J.M.; Sormunen, R.; Lippo, S.; Kaarteenaho-Wiik, R.; Soininen, R.; Myllyharju, J. Lysyl oxidase is essential for normal development and function of the respiratory system and for the integrity of elastic and collagen fibers in various tissues. Am. J. Pathol. 2005, 167, 927-936. [CrossRef]

49. Gacheru, S.N.; Thomas, K.M.; Murray, S.A.; Csiszar, K.; Smith-Mungo, L.I.; Kagan, H.M. Transcriptional and post-transcriptional control of lysyl oxidase expression in vascular smooth muscle cells: Effects of TGF-beta 1 and serum deprivation. J. Cell Biochem. 1997, 65, 395-407. [CrossRef]

50. Green, R.S.; Lieb, M.E.; Weintraub, A.S.; Gacheru, S.N.; Rosenfield, C.L.; Shah, S.; Kagan, H.M.; Taubman, M.B. Identification of lysyl oxidase and other platelet-derived growth factor-inducible genes in vascular smooth muscle cells by differential screening. Lab. Invest. 1995, 73, 476-482.

51. Qi, Y.X.; Jiang, J.; Jiang, X.H.; Wang, X.D.; Ji, S.Y.; Han, Y.; Long, D.K.; Shen, B.R.; Yan, Z.Q.; Chien, S.; et al. PDGF-BB and TGF-\{beta\}1 on cross-talk between endothelial and smooth muscle cells in vascular remodeling induced by low shear stress. Proc. Natl. Acad. Sci. USA 2011, 108, 1908-1913. [CrossRef] [PubMed]

52. Martínez, E.; Rodríguez, C.; Miana, M.; Jurado-López, R.; Bartolomé, M.V.; Luaces, M.; Islas, F.; Martínez-González, J.; López-Andrés, N.; Cachofiero, V. The lysyl oxidase inhibitor $\beta$-aminopropionitrile reduces leptin profibrotic effects and ameliorates cardiovascular remodeling in diet-induced obesity in rats. J. Mol. Cell Cardiol. 2016, 92, 96-104. [CrossRef] [PubMed]

53. Atsawasuwan, P.; Mochida, Y.; Katafuchi, M.; Kaku, M.; Fong, K.S.; Csiszar, K.; Yamauchi, M. Lysyl oxidase binds transforming growth factor-beta and regulates its signaling via amine oxidase activity. J. Biol. Chem. 2008, 283, 34229-34240. [CrossRef]

54. Weissen-Plenz, G.; Eschert, H.; Volker, W.; Sindermann, J.R.; Beissert, S.; Robenek, H.; Scheld, H.H.; Breithardt, G. Granulocyte macrophage colony-stimulating factor deficiency affects vascular elastin production and integrity of elastic lamellae. J. Vasc. Res. 2008, 45, 103-110. [CrossRef]

55. Lucero, H.A.; Kagan, H.M. Lysyl oxidase: An oxidative enzyme and effector of cell function. Cell Mol. Life Sci. 2006, 63, 2304-2316. [CrossRef] [PubMed] 
56. Li, W.; Liu, G.; Chou, I.N.; Kagan, H.M. Hydrogen peroxide-mediated, lysyl oxidase-dependent chemotaxis of vascular smooth muscle cells. J. Cell Biochem. 2000, 78, 550-557. [CrossRef]

57. Lucero, H.A.; Ravid, K.; Grimsby, J.L.; Rich, C.B.; DiCamillo, S.J.; Mäki, J.M.; Myllyharju, J.; Kagan, H.M. Lysyl oxidase oxidizes cell membrane proteins and enhances the chemotactic response of vascular smooth muscle cells. J. Biol. Chem. 2008, 283, 24103-24117. [CrossRef]

58. Johnson, C.D.; Balagurunathan, Y.; Dougherty, E.R.; Afshari, C.A.; He, Q.; Ramos, K.S. Insight into redox-regulated gene networks in vascular cells. Bioinformation 2007, 1, 379-383. [CrossRef]

59. Nuthakki, V.K.; Fleser, P.S.; Malinzak, L.E.; Seymour, M.L.; Callahan, R.E.; Bendick, P.J.; Zelenock, G.B.; Shanley, C.J. Lysyl oxidase expression in a rat model of arterial balloon injury. J. Vasc. Surg. 2004, 40, 123-129. [CrossRef]

60. Brasselet, C.; Durand, E.; Addad, F.; Al Haj Zen, A.; Smeets, M.B.; Laurent-Maquin, D.; Bouthors, S.; Bellon, G.; de Kleijn, D.; Godeau, G.; et al. Collagen and elastin cross-linking: A mechanism of constrictive remodeling after arterial injury. Am. J. Physiol. Heart Circ. Physiol. 2005, 289, H2228-H2233. [CrossRef]

61. Hurtado, P.A.; Vora, S.; Sume, S.S.; Yang, D.; St Hilaire, C.; Guo, Y.; Palamakumbura, A.H.; Schreiber, B.M.; Ravid, K.; Trackman, P.C. Lysyl oxidase propeptide inhibits smooth muscle cell signaling and proliferation. Biochem. Biophys. Res. Commun. 2008, 366, 156-161. [CrossRef] [PubMed]

62. Orriols, M.; Guadall, A.; Galán, M.; Martí-Pàmies, I.; Varona, S.; Rodríguez-Calvo, R.; Briones, A.M.; Navarro, M.A.; de Diego, A.; Osada, J.; et al. Lysyl oxidase (LOX) in vascular remodelling. Insight from a new animal model. Thromb. Haemost. 2014, 112, 812-824. [CrossRef] [PubMed]

63. Varona, S.; Orriols, M.; Galan, M.; Cañes, L.; Aguilo, S.; Sirvent, M.; Martínez-González, J.; Rodríguez, C. Lysyl oxidase (LOX) limits VSMC proliferation and neointimal thickening through its extracellular enzymatic activity. Sci. Rep. 2018, 8, 13258. [CrossRef] [PubMed]

64. Li, W.; Nellaiappan, K.; Strassmaier, T.; Graham, L.; Thomas, K.M.; Kagan, H.M. Localization and activity of lysyl oxidase within nuclei of fibrogenic cells. Proc. Natl. Acad. Sci. USA 1997, 94, 12817-12822. [CrossRef] [PubMed]

65. Nellaiappan, K.; Risitano, A.; Liu, G.; Nicklas, G.; Kagan, H.M. Fully processed lysyl oxidase catalyst translocates from the extracellular space into nuclei of aortic smooth-muscle cells. J. Cell Biochem. 2000, 79, 576-582. [CrossRef]

66. Giampuzzi, M.; Botti, G.; Di Duca, M.; Arata, L.; Ghiggeri, G.; Gusmano, R.; Ravazzolo, R.; Di Donato, A. Lysyl oxidase activates the transcription activity of human collagene III promoter. Possible involvement of Ku antigen. J. Biol. Chem. 2000, 275, 36341-36349. [CrossRef]

67. Giampuzzi, M.; Oleggini, R.; Di Donato, A. Demonstration of in vitro interaction between tumor suppressor lysyl oxidase and histones H1 and H2: Definition of the regions involved. Biochim. Biophys. Acta 2003, 1647, 245-251. [CrossRef]

68. Oleggini, R.; Gastaldo, N.; Di Donato, A. Regulation of elastin promoter by lysyl oxidase and growth factors: Cross control of lysyl oxidase on TGF-beta1 effects. Matrix Biol. 2007, 26, 494-505. [CrossRef]

69. Saad, F.A.; Torres, M.; Wang, H.; Graham, L. Intracellular lysyl oxidase: Effect of a specific inhibitor on nuclear mass in proliferating cells. Biochem. Biophys. Res. Commun. 2010, 396, 944-999. [CrossRef]

70. Detrano, R.; Guerci, A.D.; Carr, J.J.; Bild, D.E.; Burke, G.; Folsom, A.R.; Liu, K.; Shea, S.; Szklo, M.; Bluemke, D.A.; et al. Coronary calcium as a predictor of coronary events in four racial or ethnic groups. N. Engl. J. Med. 2008, 358, 1336-1345. [CrossRef]

71. Peters, S.A.; Bakker, M.; den Ruijter, H.M.; Bots, M.L. Added value of CAC in risk stratification for cardiovascular events: A systematic review. Eur. J. Clin. Invest. 2012, 42, 110-116. [CrossRef] [PubMed]

72. Greenland, P.; LaBree, L.; Azen, S.P.; Doherty, T.M.; Detrano, R.C. Coronary artery calcium score combined with Framingham score for risk prediction in asymptomatic individuals. JAMA 2004, 291, 210-215. [CrossRef] [PubMed]

73. Sugitani, H.; Wachi, H.; Mecham, R.P.; Seyama, Y. Accelerated calcification represses the expression of elastic fiber components and lysyl oxidase in cultured bovine aortic smooth muscle cells. J. Atheroscler. Thromb. 2002, 9, 292-298. [CrossRef] [PubMed]

74. Hutson, H.N.; Marohl, T.; Anderson, M.; Eliceiri, K.; Campagnola, P.; Masters, K.S. Calcific aortic valve disease is associated with layer-specific alterations in collagen architecture. PLoS ONE 2016, 11, e0163858. [CrossRef] [PubMed] 
75. Willum-Hansen, T.; Staessen, J.A.; Torp-Pedersen, C.; Rasmussen, S.; Thijs, L.; Ibsen, H.; Jeppesen, J. Prognostic value of aortic pulse wave velocity as index of arterial stiffness in the general population. Circulation 2006, 113, 664-670. [CrossRef] [PubMed]

76. Laurent, S.; Cockcroft, J.; Van Bortel, L.; Boutouyrie, P.; Giannattasio, C.; Hayoz, D.; Pannier, B.; Vlachopoulos, C.; Wilkinson, I.; Struijker-Boudier, H. European Network for Non-invasive Investigation of Large Arteries. Expert consensus document on arterial stiffness: Methodological issues and clinical applications. Eur. Heart J. 2006, 27, 2588-2605. [CrossRef] [PubMed]

77. Mitchell, G.F. Arterial stiffness and hypertension: Chicken or egg? Hypertension 2014, 64, 210-214. [CrossRef]

78. Martínez-Revelles, S.; García-Redondo, A.B.; Avendaño, M.S.; Varona, S.; Palao, T.; Orriols, M.; Roque, F.R.; Fortuño, A.; Touyz, R.M.; Martínez-González, J.; et al. Lysyl oxidase induces vascular oxidative stress and contributes to arterial stiffness and abnormal elastin structure in hypertension: Role of p38MAPK. Antioxid. Redox Signal. 2017, 27, 379-397. [CrossRef]

79. González, J.M.; Briones, A.M.; Starcher, B.; Conde, M.V.; Somoza, B.; Daly, C.; Vila, E.; McGrath, I.; González, M.C.; Arribas, S.M. Influence of elastin on rat small artery mechanical properties. Exp. Physiol. 2005, 90, 463-468. [CrossRef]

80. Eberson, L.S.; Sanchez, P.A.; Majeed, B.A.; Tawinwung, S.; Secomb, T.W.; Larson, D.F. Effect of lysyl oxidase inhibition on angiotensin II-induced arterial hypertension, remodeling, and stiffness. PLoS ONE 2015, 10, e0124013. [CrossRef]

81. Staiculescu, M.C.; Kim, J.; Mecham, R.P.; Wagenseil, J.E. Mechanical behavior and matrisome gene expression in the aneurysm-prone thoracic aorta of newborn lysyl oxidase knockout mice. Am. J. Physiol. Heart Circ. Physiol. 2017, 313, H446-H456. [CrossRef] [PubMed]

82. Levy, D.; Larson, M.G.; Benjamin, E.J.; Newton-Cheh, C.; Wang, T.J.; Hwang, S.J.; Vasan, R.S.; Mitchell, G.F. Framingham heart study $100 \mathrm{~K}$ project: Genome-Wide associations for blood pressure and arterial stiffness. BMC Med. Genet. 2007, 8, S3. [CrossRef] [PubMed]

83. Steppan, J.; Wang, H.; Bergman, Y.; Rauer, M.J.; Tan, S.; Jandu, S.; Nandakumar, K.; Barreto-Ortiz, S.; Cole, R.N.; Boronina, T.N.; et al. Lysyl oxidase-like 2 depletion is protective in age-associated vascular stiffening. Am. J. Physiol. Heart Circ. Physiol. 2019, 317, H49-H59. [CrossRef] [PubMed]

84. Qiu, H.; Zhu, Y.; Sun, Z.; Trzeciakowski, J.P.; Gansner, M.; Depre, C.; Resuello, R.R.; Natividad, F.F.; Hunter, W.C.; Genin, G.M.; et al. Short communication: Vascular smooth muscle cell stiffness as a mechanism for increased aortic stiffness with aging. Circ. Res. 2010, 107, 615-619. [CrossRef] [PubMed]

85. Bignon, M.; Pichol-Thievend, C.; Hardouin, J.; Malbouyres, M.; Bréchot, N.; Nasciutti, L.; Barret, A.; Teillon, J.; Guillon, E.; Etienne, E.; et al. Lysyl oxidase-like protein-2 regulates sprouting angiogenesis and type IV collagen assembly in the endothelial basement membrane. Blood 2011, 118, 3979-3989. [CrossRef] [PubMed]

86. Del Toro, R.; Prahst, C.; Mathivet, T.; Siegfried, G.; Kaminker, J.S.; Larrivee, B.; Breant, C.; Duarte, A.; Takakura, N.; Fukamizu, A.; et al. Identification and functional analysis of endothelial tip cell-enriched genes. Blood 2010, 116, 4025-4033. [CrossRef]

87. De Jong, O.G.; van der Waals, L.M.; Kools, F.R.W.; Verhaar, M.C.; van Balkom, B.W.M. Lysyl oxidase-like 2 is a regulator of angiogenesis through modulation of endothelial-to-mesenchymal transition. J. Cell Physiol. 2019, 234, 10260-10269. [CrossRef]

88. Zaffryar-Eilot, S.; Marshall, D.; Voloshin, T.; Bar-Zion, A.; Spangler, R.; Kessler, O.; Ghermazien, H.; Brekhman, V.; Suss-Toby, E.; Adam, D.; et al. Lysyl oxidase-like-2 promotes tumour angiogenesis and is a potential therapeutic target in angiogenic tumours. Carcinogenesis 2013, 34, 2370-2379. [CrossRef]

89. Barry-Hamilton, V.; Spangler, R.; Marshall, D.; McCauley, S.; Rodriguez, H.M.; Oyasu, M.; Mikels, A.; Vaysberg, M.; Ghermazien, H.; Wai, C.; et al. Allosteric inhibition of lysyl oxidase-like-2 impedes the development of a pathologic microenvironment. Nat. Med. 2010, 16, 1009-1017. [CrossRef]

90. Chang, J.; Lucas, M.C.; Leonte, L.E.; Garcia-Montolio, M.; Singh, L.B.; Findlay, A.D.; Deodhar, M.; Foot, J.S.; Jarolimek, W.; Timpson, P.; et al. Pre-clinical evaluation of small molecule LOXL2 inhibitors in breast cancer. Oncotarget 2017, 8, 26066-26078. [CrossRef]

91. Baker, A.M.; Bird, D.; Welti, J.C.; Gourlaouen, M.; Lang, G.; Murray, G.I.; Reynolds, A.R.; Cox, T.R.; Erler, J.T. Lysyl oxidase plays a critical role in endothelial cell stimulation to drive tumor angiogenesis. Cancer Res. 2013, 73, 583-594. [CrossRef] [PubMed] 
92. Osawa, T.; Ohga, N.; Akiyama, K.; Hida, Y.; Kitayama, K.; Kawamoto, T.; Yamamoto, K.; Maishi, N.; Kondoh, M.; Onodera, Y.; et al. Lysyl oxidase secreted by tumour endothelial cells promotes angiogenesis and metastasis. Br. J. Cancer. 2013, 109, 2237-2247. [CrossRef] [PubMed]

93. Rossow, L.; Veitl, S.; Vorlová, S.; Wax, J.K.; Kuhn, A.E.; Maltzahn, V.; Upcin, B.; Karl, F.; Hoffmann, H.; Gätzner, S.; et al. LOX-catalyzed collagen stabilization is a proximal cause for intrinsic resistance to chemotherapy. Oncogene 2018, 37, 4921-4940. [CrossRef] [PubMed]

94. Nareshkumar, R.N.; Sulochana, K.N.; Coral, K. Inhibition of angiogenesis in endothelial cells by human lysyl oxidase propeptide. Sci. Rep. 2018, 8, 10426. [CrossRef]

95. Li, R.; Wang, Y.; Zhang, X.; Feng, M.; Ma, J.; Li, J.; Yang, X.; Fang, F.; Xia, Q.; Zhang, Z.; et al. Exosome-mediated secretion of LOXL4 promotes hepatocellular carcinoma cell invasion and metastasis. Mol. Cancer. 2019, 18, 18. [CrossRef]

96. Kucharzewska, P.; Christianson, H.C.; Welch, J.E.; Svensson, K.J.; Fredlund, E.; Ringnér, M.; Mörgelin, M.; Bourseau-Guilmain, E.; Bengzon, J.; Belting, M. Exosomes reflect the hypoxic status of glioma cells and mediate hypoxia-dependent activation of vascular cells during tumor development. Proc. Natl. Acad. Sci. USA 2013, 110, 7312-7317. [CrossRef]

97. Kore, R.A.; Edmondson, J.L.; Jenkins, S.V.; Jamshidi-Parsian, A.; Dings, R.P.M.; Reyna, N.S.; Griffin, R.J. Hypoxia-derived exosomes induce putative altered pathways in biosynthesis and ion regulatory channels in glioblastoma cells. Biochem. Biophys. Rep. 2018, 14, 104-113. [CrossRef]

98. González-Santamaría, J.; Villalba, M.; Busnadiego, O.; López-Olañeta, M.M.; Sandoval, P.; Snabel, J.; López-Cabrera, M.; Erler, J.T.; Hanemaaijer, R.; Lara-Pezzi, E.; et al. Matrix cross-linking lysyl oxidases are induced in response to myocardial infarction and promote cardiac dysfunction. Cardiovasc. Res. 2016, 109, 67-78. [CrossRef]

99. Badenhorst, D.; Maseko, M.; Tsotetsi, O.J.; Naidoo, A.; Brooksbank, R.; Norton, G.R.; Woodiwiss, A.J. Cross-linking influences the impact of quantitative changes inmyocardial collagen on cardiac stiffness and remodelling in hypertension in rats. Cardiovasc. Res. 2003, 57, 632-641. [CrossRef]

100. Stefanon, I.; Valero-Muñoz, M.; Fernandes, A.A.; Ribeiro, R.F., Jr.; Rodríguez, C.; Miana, M.; Martínez-González, J.; Spalenza, J.S.; Lahera, V.; Vassallo, P.F.; et al. Left and right ventricle late remodeling following myocardial infarction in rats. PLOS ONE 2013, 8, e64986. [CrossRef]

101. Norton, G.R.; Tsotetsi, J.; Trifunovic, B.; Hartford, C.; Candy, G.P.; Woodiwiss, A.J. Myocardial stiffness is attributed to alterations in cross-linked collagen rather than total collagen or phenotypes in spontaneously hypertensive rats. Circulation 1997, 96, 1991-1998. [CrossRef] [PubMed]

102. López, B.; Querejeta, R.; González, A.; Larman, M.; Díez, J. Collagen cross-linking but not collagen amount associates with elevated filling pressures in hypertensive patients with stage $C$ heart failure: Potential role of lysyl oxidase. Hypertension 2012, 60, 677-683. [CrossRef] [PubMed]

103. Kasner, M.; Westermann, D.; Lopez, B.; Gaub, R.; Escher, F.; Kühl, U.; Schultheiss, H.P.; Tschöpe, C. Diastolic tissue Doppler indexes correlate with the degree of collagen expression and crosslinking in heart failure and normal ejection fraction. J. Am. Coll. Cardiol. 2011, 57, 977-985. [CrossRef] [PubMed]

104. Galán, M.; Varona, S.; Guadall, A.; Orriols, M.; Navas, M.; Aguiló, S.; de Diego, A.; Navarro, M.A.; García-Dorado, D.; Rodríguez-Sinovas, A.; et al. Lysyl oxidase over-expression accelerates cardiac remodelling and aggravates angiotensin II-induced hypertrophy. FASEB J. 2017, 31, 3787-3799. [CrossRef] [PubMed]

105. Yang, J.; Savvatis, K.; Kang, J.S.; Fan, P.; Zhong, H.; Schwartz, K.; Barry, V.; Mikels-Vigdal, A.; Karpinski, S.; Kornyeyev, D.; et al. Targeting LOXL2 for cardiac interstitial fibrosis and heart failure treatment. Nat. Commun. 2016, 7, 13710. [CrossRef]

106. Van Putten, S.; Shafieyan, Y.; Hinz, B. Mechanical control of cardiac myofibroblasts. J. Mol. Cell Cardiol. 2016, 93, 133-142. [CrossRef]

107. Voloshenyuk, T.G.; Landesman, E.S.; Khoutorova, E.; Hart, A.D.; Gardner, J.D. Induction of cardiac fibroblast lysyl oxidase by TGF- $\beta 1$ requires PI3K/Akt, Smad3, and MAPK signaling. Cytokine 2011, 55, 90-97. [CrossRef]

108. Lu, M.; Qin, Q.; Yao, J.; Sun, L.; Qin, X. Induction of LOX by TGF- $\beta 1 /$ Smad/AP-1 signaling aggravates rat myocardial fibrosis and heart failure. IUBMB Life 2019. [CrossRef]

109. Kubota, T.; McTiernan, C.F.; Frye, C.S.; Slawson, S.E.; Lemster, B.H.; Koretsky, A.P.; Demetris, A.J.; Feldman, A.M. Dilated cardiomyopathy in transgenic mice with cardiac-specific overexpression of tumor necrosis factor-alpha. Circ. Res. 1997, 81, 627-635. [CrossRef] 
110. Voloshenyuk, T.G.; Hart, A.D.; Khoutorova, E.; Gardner, J.D. TNF- $\alpha$ increases cardiac fibroblast lysyl oxidase expression through TGF- $\beta$ and PI3Kinase signaling pathways. Biochem. Biophys. Res. Commun. 2011, 413, 370-375. [CrossRef]

111. López, B.; González, A.; Lindner, D.; Westermann, D.; Ravassa, S.; Beaumont, J.; Gallego, I.; Zudaire, A.; Brugnolaro, C.; Querejeta, R.; et al. Osteopontin-mediated myocardial fibrosis in heart failure: A role for lysyl oxidase? Cardiovasc. Res. 2013, 99, 111-120. [CrossRef] [PubMed]

112. Yu, Q.; Vazquez, R.; Zabadi, S.; Watson, R.R.; Larson, D.F. T-lymphocytes mediate left ventricular fibrillar collagen cross-linking and diastolic dysfunction in mice. Matrix Biol. 2010, 29, 511-518. [CrossRef] [PubMed]

113. Ahsan, T.; Lottman, L.M.; Harwood, F.; Amiel, D.; Sah, R.L. Integrative cartilage repair: Inhibition by beta-aminopropionitrile. J. Orthop. Res. 1999, 17, 850-857. [CrossRef] [PubMed]

114. Spencer, P.S.; Schaumburg, H.H. Lathyrism: A neurotoxic disease. Neurobehav. Toxicol. Teratol. 1983, 5, 625-629. [PubMed]

115. Turecek, C.; Fratzl-Zelman, N.; Rumpler, M.; Buchinger, B.; Spitzer, S.; Zoehrer, R.; Durchschlag, E.; Klaushofer, K.; Paschalis, E.P.; Varga, F. Collagen cross-linking influences osteoblastic differentiation. Calcif. Tissue Int. 2008, 82, 392-400. [CrossRef] [PubMed]

116. Dasler, W. Isolation of toxic crystals from sweet peas (Lathyrus odoratus). Science 1954, 120, 307-308. [CrossRef] [PubMed]

117. Fickert, P. Is this the last requiem for Simtuzumab? Hepatology 2019, 69, 476-479. [CrossRef]

118. Rowbottom, M.W.; Bain, G.; Calderon, I.; Lasof, T.; Lonergan, D.; Lai, A.; Huang, F.; Darlington, J.; Prodanovich, P.; Santini, A.M.; et al. Identification of 4-(aminomethyl)-6-(trifluoromethyl)-2-(phenoxy) pyridine derivatives as potent, selective, and orally efficacious inhibitors of the copper-dependent amine oxidase, lysyl oxidase-like 2 (LOXL2). J. Med. Chem. 2017, 60, 4403-4423. [CrossRef]

119. López, B.; Querejeta, R.; González, A.; Beaumont, J.; Larman, M.; Díez, J. Impact of treatment on myocardial lysyl oxidase expression and collagen cross-linking in patients with heart failure. Hypertension 2009, 53, 236-242. [CrossRef]

120. Miguel-Carrasco, J.L.; Beaumont, J.; San José, G.; Moreno, M.U.; López, B.; González, A.; Zalba, G.; Díez, J.; Fortuño, A.; Ravassa, S. Mechanisms underlying the cardiac antifibrotic effects of losartan metabolites. Sci. Rep. 2017, 7, 41865. [CrossRef]

(C) 2019 by the authors. Licensee MDPI, Basel, Switzerland. This article is an open access article distributed under the terms and conditions of the Creative Commons Attribution (CC BY) license (http://creativecommons.org/licenses/by/4.0/). 